\title{
Psicanálise Funciona? Avaliando a Prova Cabal de Christian Dunker
}

1. Clarice de Medeiros Chaves

Ferreira

Laboratório de Investigações em Neurociência Clínica (UFMG).

Laboratório de Avaliação e

Intervenção em Saúde (UFMG).

Universidade FUMEC, Belo Horizonte, MG - Brasil.

2. Vitor Douglas de Andrade Laboratório de Investigações em Neurociência Clínica (UFMG).

Universidade Federal de Minas

Gerais, Belo Horizonte, MG - Brasil.

3. Thiago Mácimo Pereira

Pesquisador Independente, Teófilo Otoni, MG - Brasil.
4. João Pedro Parreira

Rodrigues

Núcleo de Neurociências.

Universidade Federal de Minas

Gerais, Belo Horizonte, MG - Brasil.

\section{Vinícius Figueiredo de} Oliveira

Laboratório de Psicologia Médica e Neuropsicologia. Universidade Federal de Minas Gerais, Belo Horizonte, MG - Brasil

6. Camila Batista Peixoto Laboratório de Neuropsicologia do Desenvolvimento. Universidade Federal de Minas Gerais, Belo Horizonte, MG - Brasil.

7. Gustavo Carvalho Fretta Centro Universitário Barriga Verde, Orleans, SC - Brasil.

\section{Resumo}

Discussões sobre a cientificidade e eficácia da psicanálise têm se popularizado, impulsionadas em parte pelo movimento da Psicologia Baseada em Evidências. Há casos em que determinados estudos são citados para atestar a eficácia de terapias psicanalíticas ou psicodinâmicas, mas pouco é discutido sobre sua qualidade metodológica, característica crucial para a justificação das intervenções. Neste artigo realizamos uma avaliação da qualidade metodológica de 17 artigos denominados como "provas cabais a favor da eficácia da psicanálise" pelo psicanalista Christian Dunker. Conduzimos avaliações pareadas e independentes sobre um estudo quase-experimento com o instrumento ROBINS-I, três ensaios clínicos randomizados com o instrumento RoB 2 e duas revisões sistemáticas, além de seis metanálises, com o instrumentos AMSTAR 2. Também discutimos a pertinência de um relato de experiências e quatro revisões narrativas. Além disso, esclarecemos confusões comuns sobre as diferenças entre avaliar a cientificidade de uma teoria e avaliar a eficácia de uma terapia, bem como as diferenças entre terapias psicanalíticas e psicodinâmicas. Ao final, os resultados mostraram que todos os estudos listados por Dunker ou obtinham a pior classificação possível para o respectivo delineamento, ou não eram de delineamentos adequados para 
responder sobre eficácia psicoterápica, o que impede que sejam tratados como boas provas a favor de terapias psicodinâmicas ou psicanalíticas.

Palavras-chave: psicanálise, psicodinâmica, eficácia, qualidade metodológica.

\section{Abstract}

Discussions about the scientific status and effectiveness of psychoanalysis are becoming more popular in Brazil, driven in part by the Evidence-Based Psychology movement. There are cases in which certain studies are cited to attest to the effectiveness of psychoanalytic or psychodynamic therapies, but little is discussed about their methodological quality, which is a crucial feature to justify the interventions. In this article we have evaluated the methodological quality of 17 articles claimed to be the "ultimate proof of the effectiveness of psychoanalysis" by the psychoanalyst Christian Dunker. We have conducted paired and independent evaluations on a quasi-experiment study with the ROBINS-I instrument, three randomized clinical trials with the RoB 2 instrument, and two systematic reviews and six meta-analyses with the AMSTAR 2 instrument. The relevance of an experience report and four narrative reviews were also discussed. In addition, we have clarified common misunderstandings about the differences between assessing the scientific status of a theory and the effectiveness of a therapy, as well as the differences between psychoanalytic and psychodynamic therapies. In the end, the results have shown that all the studies listed by Dunker either obtained the worst possible classification for the respective design or their designs could not properly address psychotherapeutic efficacy, which prevents them from being treated as good evidence in favor of psychodynamic or psychoanalytic psychotherapies.

Keywords: psychoanalysis, psychodynamic, efficacy, methodological quality. 


\section{Introdução}

Psicanálise é ciência? Ela funciona? Questões como essas têm ganhado certa popularidade, e isso se deve muito à Psicologia Baseada em Evidências: um movimento que busca se orientar pelos melhores achados científicos disponíveis sobre as teorias e intervenções na área da psicologia, sem com isso desconsiderar a importância dos valores, preferências, contexto e subjetividade dos clientes e a perícia dos profissionais em suas práticas. No entanto, apesar desse movimento estar crescendo na psicologia, o seu desenvolvimento não segue sem ataques.

Há alguns meses o professor e psicanalista Christian Dunker lançou um vídeo em seu canal do YouTube intitulado "Psicanálise Baseada em Evidências" (Dunker, 2021). Nele, Dunker:

- fez críticas ao movimento da Psicologia Baseada em Evidências (chamando-a inclusive de "praga");

- tentou defender que a psicanálise possui embasamento científico;

- expressou ofensas pessoais a estudantes e profissionais, entre eles:

- Carlos Orsi, um dos cofundadores do Instituto Questão de Ciência, e

- Clarice Ferreira e Vitor Andrade, coautores deste documento;

- e chegou mesmo a ameaçar publicamente de destituição o ex-presidente da Sociedade Brasileira de Psicologia, Ronaldo Pilati, com base em uma informação falsa sobre seu livro "Ciência e pseudociência: por que acreditamos naquilo em que queremos acreditar" (Pilati, 2018).

A maior parte dos argumentos de Dunker já foram respondidos numa ocasião anterior, no vídeo-resposta "Psicanálise Baseada em Evidências? Uma resposta ao Christian Dunker", no canal de divulgação científica Psicolosofia (2021) (criado por um dos coautores: Clarice Ferreira). Entretanto, ainda resta um ponto a ser abordado: os estudos de eficácia da terapia psicanalítica (ou melhor, neste caso, psicodinâmica).

\section{Os possíveis resultados favoráveis de uma psicoterapia dão status científico à sua teoria?}

Antes de iniciarmos a discussão sobre os dados empíricos, é proveitoso fazer algumas observações relativas a teoria vs. prática psicológica. Apesar da importância em saber se um determinado tratamento ou terapia possui boas evidências de eficácia, isso não é o mesmo que discutir se a teoria por detrás dele ou dela é científica. Aqui é importante fazer a seguinte distinção: uma terapia diz respeito a um conjunto de técnicas que o profissional realiza em uma determinada intervenção em saúde; já uma teoria é um conjunto de afirmações com o objetivo de descrever ou explicar um determinado aspecto da realidade.

Tome como exemplo a Terapia Cognitivo-Comportamental (TCC), caracterizada como uma intervenção psicológica. Mesmo que ela seja 
empiricamente sustentada para o tratamento de algum transtorno em especial, isso, por si só, não provaria a Psicologia Cognitiva - teoria que se acredita fundamentar a TCC. Isso é porque as afirmações teóricas da Psicologia Cognitiva tentam explicar a psicologia humana; e o faz de um modo geral tal que é preciso ir muito além das evidências psicoterápicas para afirmar que a teoria, ou mesmo partes dela, está adequadamente justificada. Em outras palavras, pode ser o caso que tenhamos boas evidências a favor da TCC para o tratamento de certos transtornos, mas que a Psicologia Cognitiva não seja a melhor alternativa teórica. Vice-versa, pode ser também o caso que a Psicologia Cognitiva seja a nossa melhor teoria para compreender o comportamento humano, mas que a TCC, que se supõe ser uma psicoterapia fundamentada pela Psicologia Cognitiva, não seja de fato eficaz para o que pretende ser. Isso pode gerar confusão, especialmente, para os nossos propósitos, nas discussões sobre a cientificidade da psicanálise, pois a teoria psicanalítica é construída exatamente a partir dos casos clínicos de seus proponentes. Entretanto, essas evidências clínicas, ainda que sugerissem que a psicoterapia psicanalítica é eficaz, ainda seriam uma base muito fraca para dar suporte à teoria psicanalítica.

Para ilustrar como que a mera constatação de eficácia de uma intervenção tende a ser insatisfatória para a confirmação de uma teoria, considere o seguinte exemplo: foi descoberta uma nova espécie de planta que produz determinada seiva dentro de seu caule. Biólogos e bioquímicos, ao descobrirem o novo espécime vegetal, realizam uma análise química dos compostos da seiva. Assim, descobrem que, entre os diversos componentes que a formam, há uma nova substância nunca antes observada na natureza, chamada a partir de agora de substância X. Posteriormente, pesquisadores da área farmacêutica fazem testes extremamente rigorosos com a seiva, e descobrem que um creme que fabricam a partir dela funciona como um tratamento excepcional para dermatoses. Desse modo, esses mesmos farmacêuticos desenvolvem a teoria de que o creme produz esses efeitos devido à substância $X$.

A constatação da eficácia nos permitiria concluir que a teoria defendida por esses pesquisadores é a mais adequada? Certamente não, pois apesar de, como suposto, o creme funcionar como mostram os testes, o mecanismo causal por trás disso não está necessariamente em substância $X$; pode estar, digamos, em substância $Y$ também contida na seiva e inclusive muito mais comum em outros organismos vegetais eficazes contra dermatoses. Chamamos atenção para o fato de que isso poderia não ser nem mesmo conhecido, porque tais plantas que contém a substância $Y$ nunca foram adequadamente investigadas para esses fins e isso nem posto à prova em outros momentos. Em suma, para estabelecer que uma teoria é a mais adequada, não basta esta estabelecer a eficácia da intervenção cujos mecanismos causais ela explica; é necessário que haja outras evidências que apontem que a explicação dada por ela é realmente a mais provável em comparação com as concorrentes.

Outro exemplo que envolve a interferência de confundidores pode ser o seguinte: suponha que uma determinada civilização tenha o costume de balançar as 
ramas das mandiocas antes do plantio acreditando que essa seja uma prática que colabora para seu crescimento e que, ao mesmo tempo, a civilização vizinha não realize a prática. Suponha, além disso, que de fato, na primeira civilização, todas as mandiocas acabam crescendo de forma saudável após a realização da prática, enquanto que, na segunda, nascem mandiocas de pior qualidade. Apesar do que as nossas intuições nos levam a crer, essas informações não são base suficiente para concluir que o balançar das ramas é a verdadeira causa do desfecho observado: por exemplo, pode haver entre as duas civilizações diferenças de profundidade do plantio, de características do solo, de pluviosidade ou de existência de pragas.

No contexto da psicologia, existem diversas razões pelas quais uma terapia pode mostrar algum tipo de resultado, para além daquelas propostas pela teoria que a embasa. Variáveis podem ter impacto importante na saúde através de mecanismos diferentes dos propostos teoricamente, como a maior exposição à interações sociais (com o terapeuta e outras pessoas), o efeito placebo, o curso natural dos transtornos/doenças, expectativas, o uso de outros tratamentos paralelos e também a infinidade de exposições a outros estímulos na vida cotidiana que impactam a saúde (Benedetti, 2009).

Dada essas questões, imagine o seguinte cenário: Um psicanalista tem sucesso numa seção de análise. Ele então explica o seu bom resultado terapêutico tendo como causa a interpretação correta, alcançada em colaboração com o paciente, sobre os seus conflitos edipianos infantis, permitindo assim uma suspensão do seu recalque. Desse modo, ele crê, tal resultado prova a existência de construtos psicanalíticos como o complexo de édipo, o inconsciente psicodinâmico e o recalque. O que há de errado nisso? O problema é que, ao fazer isso, ele deixa de considerar todas as possíveis explicações alternativas para o fenômeno da melhora. O ponto é que, neste caso, para provar a existência de construtos teóricos e fenômenos específicos da teoria psicanalítica, devem ser conduzidas investigações extraclínicas desenvolvidas especificamente para investigá-los, em primeiro lugar. Caso essas investigações não possam ser realizadas; possam, mas não sejam realizadas; ou sejam, mas não apresentem uma qualidade suficiente, não estamos justificados em acreditar nos pressupostos da teoria.

Infelizmente, a possibilidade imaginada acima costuma ser a realidade: a própria Associação Psicanalítica Internacional admite que a maioria das hipóteses psicanalíticas não passou por testes empíricos, tendo portanto uma base de fundamentação obscura, além de que a principal fonte de construção da teoria consiste exatamente no trabalho clínico psicanalítico (Bernardi et al., 2015). As pouquíssimas publicações empíricas da psicanálise dizem respeito a modalidades de terapias derivadas dela (mais sobre isso na próxima seção), sendo assim as evidências extraclínicas quase inexistentes na literatura. Não existem boas evidências científicas a favor dos seus postulados teóricos, e as poucas tentativas de ao menos se fazer pesquisa empírica sobre eles, como o estudo de Shevrin et al. (2013) mencionado por Dunker, passam muito longe de oferecer boas evidências a favor da psicanálise, sem falar que têm qualidade metodológica bastante 
questionável (no caso desse estudo mencionado por Dunker, por exemplo, o tamanho amostral é ínfimo, falta de randomização e um grupo controle).

Além disso, é importante assinalar o papel que as evidências exercem de fato na teoria psicanalítica: historicamente, a psicanálise corrigiu os seus pressupostos teóricos e clínicos não com base em boas/novas evidências científicas, mas sim apenas por pressões culturais (tome como exemplo a inveja do pênis ou o status patológico da homossexualidade) (Cioffi, 2013). Dito de outro modo, as mudanças teóricas na psicanálise não ocorreram por meio da descoberta científica de que seus pressupostos eram falsos, ou da obtenção de evidências de que exigem adequações teóricas: elas correram por meio de forças não epistêmicas, como a tendência a se adequar à visão cultural da época. E, lamentavelmente, mesmo que atualmente não tenhamos boas evidências dos pressupostos psicanalíticos, este não é o tipo de razão que faria os psicanalistas abandonarem suas teorias (como é evidenciado pelo fato de que, efetivamente, eles, na maioria das vezes, não o fazem). E as evidências obtidas pelos proponentes desta doutrina acabam sendo usadas apenas para confirmar enviesadamente o que eles já acreditavam ser verdadeiro previamente.

Assim, a discussão sobre a cientificidade da psicanálise é muito pouco auxiliada pela discussão sobre a eficácia de sua proposta terapêutica, apesar de, é claro, este ser também um tópico interessante e importante a ser considerado. Quanto ao tópico da cientificidade da teoria psicanalítica, devemos fechar esta seção com uma correção de um mal-entendido recorrente sobre filosofia da ciência: o de que as críticas à cientificidade da psicanálise dependem de um popperianismo ultrapassado.

Como já havia sido mencionado no primeiro vídeo-resposta (Psicolosofia, 2021), é bem verdade que a filosofia da ciência avançou desde Popper, como podemos ver na obra organizada por Pigliucci e Boudry (2013). Assim, não é mais adequado tratar a teoria popperiana como se ela fosse a última ou melhor resposta ao problema da demarcação: o problema de distinguir ciência, pseudociência e não ciência. Mas note que, por exemplo, Clarice Ferreira (que está entre os coautores deste documento) publicou recentemente um artigo fazendo uma avaliação do status científico da psicanálise a partir de uma proposta de demarcação contemporânea, utilizando da lista de multicritérios do filósofo Sven Ove Hansson (Ferreira, 2021). O seu estudo indica que, mesmo quando fazemos uso de uma proposta de demarcação no sentido ampliado - ou seja, uma que abandona uma demarcação exclusiva para as ciências naturais e assim também considera que as humanidades (como a história, a linguística e a filosofia) podem produzir ciência - 0 resultado é o mesmo: a psicanálise continua sendo classificada como uma pseudociência, se enquadrando em todos os oito itens da lista de multicritérios (Ferreira, 2011). Assim, é um erro resumir as críticas à cientificidade da psicanálise como "aquilo que foi dito por Popper em 1963", ou tratar seus críticos como se precisassem descartar as humanidades do campo das ciências para serem consistentes. Recomendamos conferir o artigo para saber mais. 


\section{Terapia psicanalítica e psicodinâmica são a mesma coisa?}

Há alguns importantes questionamentos que devem ser feitos quando analisamos estudos de terapia psicodinâmica e tentamos fazer inferências para os resultados da psicanálise: será que, como defende Dunker (2021) em seu vídeo, todas as diferentes vertentes da psicanálise "se ajustam" no que os estudos sobre "terapias psicodinâmicas" avaliam? As técnicas ali empregadas realmente se aplicam ao que de fato fazem terapeutas de perspectivas teóricas dissidentes? Mais do que isso, mesmo que os protocolos de intervenções psicodinâmicas passem no crivo empírico de estudos apropriadamente desenhados, eles efetivamente estão orientando a atuação de terapeutas próximos da psicanálise?

Elaborar uma distinção entre a psicanálise e as teorias psicodinâmicas é uma tarefa importante, dado que esses termos são frequentemente empregados como sinônimos mesmo na literatura especializada. Um bom ponto de partida para deslindarmos possíveis confusões pode ser encontrado na definição oferecida pelo dicionário da American Psychological Association (2020) (Associação Americana de Psicologia) no verbete psychodynamic theory (teoria psicodinâmica):

"uma constelação de teorias sobre o funcionamento humano que estão baseadas na interação entre pulsões e outras forças internas do sujeito, especialmente as (e originadas das) teorias psicanalíticas desenvolvidas por Sigmund Freud e seus colegas e sucessores, como Anna Freud, Carl Jung e Melanie Klein. As teorias psicodinâmicas posteriores, mesmo que até certo ponto mantenham conceitos do interfuncionamento das pulsões e desejos, enfatizam o processo de mudança e incorporam perspectivas interpessoais e transacionais do desenvolvimento da personalidade" [tradução nossa].

A referência explícita ao agrupamento de uma miríade de perspectivas ("constelação de teorias") sobre o funcionamento humano debaixo do termo "psicodinâmica" não é de maneira nenhuma um exagero: basta observarmos que, entre as influências sobre essas terapias, encontramos famosos dissidentes da psicanálise freudiana, tais como Jung. Desse modo, o termo "teorias psicodinâmicas" se presta muito mais a reconhecer uma influência teórica de um autor-chave do que a autorizar uma igualação entre essas posições em termos de técnica. Sobre essa diversidade e suas evidentes implicações técnicas, Boswell et al. (2014) comentam:

"Como todas as crianças, os discípulos de Freud fizeram escolhas que, apesar de individuais e autônomas, refletem sua influência de um modo ou de outro. Alguns decidiram seguir fielmente as formulações originais de Freud, outros deram um foco intenso em um ou mais aspectos, e diversos deles reagiram contra princípios básicos enquanto mantiveram outros" [tradução nossa].

Se tomadas enquanto práticas uniformes, as teorias psicodinâmicas incorrem no sério risco de prescrever práticas extremamente inespecíficas que se fiam mais na engenhosidade de cada terapeuta do que em um direcionamento claro sobre o que fazer frente a uma determinada demanda. Por esse motivo, acaba sendo também um erro dizer que, caso a eficácia de terapias psicodinâmicas fosse atestada por boas provas, isso implicaria que todas as modalidades de psicanálise 
também gozam do mesmo nível de evidências psicoterápicas. Além disso, é válido ressaltar novamente: avaliar a eficácia psicoterápica é diferente de avaliar a cientificidade de sua teoria.

\section{Objetivo e Método}

\section{Justificativa}

No presente texto, teremos como foco a discussão sobre alguns estudos de eficácia psicoterápica de abordagens da vertente psicodinâmica. Já havíamos, em um artigo anterior publicado na Revista Questão de Ciência (Andrade \& Ferreira, 2021), criticado a metanálise mais famosa de Leichsenring e Rabung (2008) por falhar em cumprir todos os critérios de qualidade estipulados para uma investigação do tipo pelo instrumento AMSTAR, o qual explicaremos mais à frente (Littell \& Shlonsky, 2010). Mesmo após nossa crítica, Dunker (2021) reiterou em seu vídeo que o trabalho de Leichsenring e Rabung foi capaz de mostrar de forma "empírica e cabal" que a psicanálise é um tratamento eficaz, além de ser mais eficaz que outras psicoterapias. Dunker (2021) raciocina que simplesmente porque existem artigos dentre os quais um publicado no JAMA (periódico da Associação Americana de Medicina) - que supostamente atestam a eficácia da psicanálise, criticá-la é uma "irresponsabilidade", fruto de "preguiça", "preconceito", "falta de ciência" e de "ética". Ele propôs, assim, uma lista de 20 artigos (que na realidade são 18, devido à repetição de dois) para provar que o tratamento psicanalítico tem respaldo científico. No restante deste texto, faremos uma análise da qualidade metodológica desses estudos, utilizando de instrumentos de avaliação próprios para cada tipo de delineamento e também levando em consideração as críticas já disponíveis na literatura.

Por que estamos fazendo isso? Principalmente porque existe um amplo desconhecimento social sobre o funcionamento da ciência e a produção científica. Dada a autoridade e o respeito que a ciência possui perante a sociedade, pode-se pensar que um artigo científico ser publicado já seria suficiente para termos boas razões para pensar que estamos justificados em acreditar em sua conclusão. Essa visão não poderia estar mais equivocada e carente de correção.

A lição a se tomar pela discussão a seguir poderia ser resumida da seguinte forma: por mais que algo tenha sido escrito na forma de um artigo e tenha sido publicado em um periódico - sim, mesmo que de grande impacto, pois o mero impacto não é boa evidência de qualidade (Serra-Garcia \& Gneezy, 2021) -, ainda não haveria garantia nenhuma de que os seus achados são realmente confiáveis. Grande parte dos artigos empíricos são mal conduzidos, possuem vieses graves ou metodologia inadequada (Ioannidis, 2012; Open Science Collaboration, 2015). Isso, no entanto, não é carta branca para sermos epistemicamente cínicos e irresponsáveis. Há uma forma de separarmos o joio do trigo, a qual consiste em fazer o trabalho duro de conduzir uma análise minuciosa para saber se o artigo em questão realmente é confiável ou é um mero embuste/equívoco; do contrário, 
poderemos estar fazendo algo danoso ao espalhar desinformação. Um exemplo desse perigo de desinformação ocorreu na CPI da COVID-19, quando foi dito por um dos proponentes do tratamento precoce que havia 2400 artigos comprovando a eficácia da cloroquina contra a COVID-19 e que isso justificaria o Ministério da Saúde liberá-lo como tratamento para a doença (UOL, 2021). Realmente podemos muito bem ter 2400 artigos meramente reportando resultados favoráveis para a cloroquina, mas, sem considerar a qualidade metodológica de tais investigações, não podemos atestá-las como sendo uma fonte confiável para defender tal conclusão.

Lamentavelmente, isso não é algo novo. Um exemplo histórico clássico foi a estratégia comercial adotada pela indústria do tabaco. Quando começaram a surgir dados científicos sugerindo que o seu produto causava câncer, a indústria do tabaco gastou milhões de dólares para financiar pesquisas favoráveis aos seus interesses para usar como contra-argumento de que havia estudos comprovando que o uso do tabaco não causava câncer (Oreskes \& Conway, 2010). Ocorre que, como de se esperar dados os conflitos de interesse envolvidos e o curso que agora sabemos que a história tomou, os estudos produzidos eram de péssima qualidade. Basear-se neles para defender o tabaco seria incorrer em irresponsabilidade com a saúde das pessoas. Essa estratégia fez com que o tabaco continuasse por muitos anos sendo vendido como um produto seguro para a saúde, mesmo havendo, à época, boas razões para pensar que era danoso. Esse caso ilustra vividamente como temos que tomar cuidado ao dizer que existem evidências a favor da eficácia de qualquer tipo de tratamento baseando-nos no simples fato de haver artigos publicados que concluem isso (cuidado esse, a propósito, que, infelizmente, Dunker não parece ter tido).

\section{Artigos e Estratégia de Avaliação}

Com relação a nossas análises, os estudos listados por Dunker (2021) foram divididos por delineamento:

- um relato de experiências (Cantin, 2009);

- quatro revisões narrativas (Shedler, 2010; Fonagy, 2015; Taylor, 2018; Yakeley, 2018);

- um prospectivo/quase-experimento (Huber et al., 2012);

- três ensaios clínicos randomizados (RCT's) (Fonagy et al., 2015; Knekt et al., 2016; Town et al., 2017);

- duas revisões sistemáticas (Leichsenring \& Klein, 2014; Leichsenring et al., 2015);

- e seis metanálises (Leichsenring et al., 2004; Leichsenring \& Rabung, 2008; Driessen et al., 2010; Leichsenring \& Rabung, 2011b; Smit et al., 2012; Abbass et al., 2014).

Os estudos de Yakeley (2018) e de Leichsenring e Rabung (2008) foram listados duas vezes originalmente por Dunker (2021), e por isso foram considerados apenas uma vez aqui, diminuindo o tamanho da lista. Havia também uma resposta 
crítica (Leichsenring et al., 2013) a uma outra metanálise (Smit et al., 2012), que atesta poucas evidências a favor da psicoterapia psicodinâmica. Por isso, focamos em realizar uma avaliação da qualidade metodológica de Smit et al. (2012) juntamente às outras metanálises. Finalmente, a metanálise de Abbass et al. (2006), citada na lista original de Dunker (2021), é na realidade uma versão já desatualizada de Abbass et al. (2014), e por isso consideramos sua versão mais recente em vez da antiga em nossa análise.

A avaliação dos artigos foi feita de forma pareada e independente, por dois revisores distintos para cada artigo. Eventuais desacordos, observados após a finalização, foram resolvidos por consenso. As exceções foram as revisões narrativas e o relato de experiências, que tiveram suas análises feitas à parte, bem como a resposta crítica, em que foi considerada primariamente a avaliação da qualidade do artigo criticado por ela. A justificativa para a não utilização de instrumentos para tais delineamentos pode ser conferida em suas respectivas seções (relato de experiências e revisões narrativas). Anteriormente à avaliação propriamente dita dos estudos de psicodinâmica, foi realizado um treinamento com todos os avaliadores: um artigo de teste (não incluído na lista original) foi selecionado para cada delineamento relevante, sendo também avaliado de forma pareada e independente.

\section{Os Instrumentos Utilizados}

Descrevemos aqui os instrumentos utilizados em nosso estudo:

- As revisões sistemáticas e metanálises foram avaliadas com a segunda versão do "A MeaSurement Tool to Assess systematic Reviews" (Ferramenta de Medida para Avaliar Revisões Sistemáticas) (AMSTAR-2), tendo como artigo teste o de Vos et al. (2015);

- os ensaios clínicos randomizados (RCT's) foram avaliados com a segunda versão do "Cochrane risk-of-bias tool for randomized trials" (Ferramenta de Risco de Vieses Cochrane para Ensaios Randomizados) (RoB 2), tendo como artigo teste o de Gladstone et al. (2020);

- e, por fim, o estudo quase-experimento foi avaliado utilizando o instrumento "Risk of Bias In Non-randomised Studies of Interventions" (Risco de Vieses em Estudos de Intervenções Não Randomizadas) (ROBINS-I), tendo como artigo teste o de Hinic et al. (2019).

Cada um desses instrumentos possui um checklist próprio a ser preenchido. De modo a aumentar nossa transparência, os documentos resultantes do nosso consenso estão disponíveis publicamente para todos os estudos avaliados, podendo ser acessados entre os materiais suplementares deste preprint.

\section{ROBINS-I}


O instrumento ROBINS-I, desenvolvido por Sterne et al. (2016), tem por finalidade avaliar o risco de viés de intervenções em estudos não randomizados. Ele se divide em sete domínios:

- viés devido a confundidores;

- viés na seleção dos participantes do estudo;

- viés na classificação das intervenções;

- viés devido a desvios das intervenções propostas;

- viés devido a dados faltantes;

- viés na medida dos resultados;

- viés na seleção dos resultados reportados.

Cada um deles pode receber a classificação de risco baixo, moderado, sério, crítico e não informado, e ao final um risco total pode ser calculado e atribuído a todo o artigo, com o mesmo tipo de classificação. Os resultados do Robins-I podem ser conferidos na Tabela 1.

\section{RoB 2}

O RoB 2 é um instrumento da Colaboração Cochrane desenvolvido por Higgins et al. (2019) que tem por finalidade avaliar o risco de viés de RCT's. O instrumento se divide em cinco domínios, sendo eles:

- vieses decorrentes do processo de randomização;

- vieses decorrentes de desvios das intervenções pretendidas;

- vieses devidos a dados faltantes;

- vieses na medida dos resultados;

- e vieses na seleção dos resultados reportados.

Cada domínio pode obter a classificação de risco de viés alto, de certa preocupação e baixo. Ao final da avaliação dos domínios individuais, é possível também fazer um julgamento final sobre o estudo dentro dos mesmos três critérios de classificação. Os resultados do RoB 2 podem ser conferidos na Tabela 2.

\section{AMSTAR 2}

O instrumento AMSTAR 2 foi proposto por Shea et al. (2017) e é uma versão mais recente do AMSTAR, que havia sido utilizado por Littell e Shlonsky (2010) anteriormente para avaliar o estudo de Leichsenring e Rabung (2008). Esse instrumento possibilita a avaliação da qualidade metodológica de revisões sistemáticas e metanálises de intervenções na área da saúde, podendo abarcar tanto aquelas que incluem ensaios clínicos randomizados (RCT's) quanto aquelas que não os incluem. Conta com 16 itens, que investigam:

- a adequação aos componentes da estratégia PICO;

- o estabelecimento de um protocolo prévio ao estudo;

- justificativas para o delineamento dos artigos incluídos;

- estratégias de busca, de extração e de seleção dos estudos e dados;

- critérios de inclusão/exclusão;

- conflitos de interesse próprios e também dos artigos incluídos; 
- riscos de viés dos estudos incluídos;

- o uso de análises estatísticas adequadas e justificativa para metanálise;

- a heterogeneidade;

- e viés de publicação.

Um resultado final pode ser calculado levando em consideração as falhas críticas e não críticas dentre os itens do instrumento:

- se possuir no máximo uma falha não crítica, o estudo pode ser considerado de alta qualidade;

- se possuir mais do que uma falha não crítica, tem qualidade moderada;

- se possuir pelo menos uma falha crítica, é de baixa qualidade;

- na presença de falha em pelo menos dois itens críticos, o resultado já pode ser classificado como sendo de qualidade criticamente baixa.

Os resultados do AMSTAR 2 podem ser conferidos na Tabela 3.

\section{Resultados e Discussão}

\section{Relato de Experiência}

Artigo considerado na seção: Cantin, 2009.

\section{Cantin, 2009}

Em meio ao conjunto de textos listados por Christian Dunker, encontra-se um relato de experiências: é um estudo não controlado em que Cantin (2009) descreve a estrutura de funcionamento de um centro de tratamento psicanalítico de psicoses, que opera na cidade de Québec, no Canadá. A autora argumenta em defesa da proposta psicanalítica e tece severas críticas a certas modalidades de tratamento psicológico, mais incisivamente às práticas baseadas em evidências em psicologia. No seio de sua crítica às outras formas de tratamento, está a crença em suas supostas limitações. Ao estabelecer que os psicóticos são acometidos por distorções da realidade, os psiquiatras, segundo a visão psicanalítica, estariam estabelecendo um modelo ideal de compreensão da realidade, o qual não dá margem para a lógica de funcionamento do inconsciente. Segundo a autora, a psicanálise

“[...] não é uma psicoterapia e não deve ser comparada a uma em seus objetos, nem em seus meios, nem em seus resultados. Faz parte de um campo diferente daquele da realidade produzida pela percepção e consciência. A psicanálise está interessada em puras produções da mente - representações mentais sem vínculo com a 'realidade', fantasias e alucinações - que, censuradas no Inconsciente, acionam e colocam em ação uma energia interna que o indivíduo experimenta como estranha a si mesmo e fora de seu controle" (Cantin, 2009, p. 312) [tradução nossa].

Esse discurso nos leva a questionar a utilidade desse material para o argumento de Dunker, uma vez que as evidências empíricas da psicanálise não 
estão em causa para a autora, além de terem a sua utilidade criticada pelos próprios psicanalistas.

Não podemos deixar de considerar as graves limitações deste estudo: não apresenta uma medida do progresso dos clientes durante o tratamento, não possui uma amostra representativa de pacientes e tampouco se presta a descrever detalhadamente os procedimentos interventivos realizados. Por esses numerosos problemas, não é possível conferir a esse estudo o status de boa evidência a favor da terapia psicanalítica.

\section{Revisões Narrativas}

Artigos considerados na seção: Shedler, 2010; Fonagy, 2015; Taylor, 2018; Yakeley, 2018.

\section{Shedler, 2010; Fonagy, 2015; Taylor, 2018; Yakeley, 2018.}

Quatro dos artigos indicados na lista podem ser caracterizados como revisões narrativas: revisões da literatura em que não há um critério prévio de seleção para estudos incluídos, que tenta discorrer sobre o conjunto de evidências disponíveis sobre algum dado assunto. Além de trazerem uma revisão da literatura, algumas delas também incluem uma parte teórica. Diferentes tipos de estudos/delineamentos servem a diferentes propósitos, e vão atender de forma mais ou menos adequada a perguntas de pesquisa diferentes. Estudos teóricos têm grande importância na ciência, auxiliando no avanço de discussões conceituais, propostas de novas definições ou reformulações das mesmas. Vemos isso em uma parte dos artigos citados: discussões sobre como definir uma terapia psicodinâmica, seus focos principais, as diferenças em relação às outras modalidades de terapia, entre outras coisas. Entretanto, as evidências que podem ser oferecidas por revisões narrativas para avaliar a eficácia de terapias em especial são extremamente limitadas.

Como vemos em Pae (2015), uma revisão narrativa difere de uma revisão sistemática por não adotar uma metodologia na seleção de quais estudos serão incluídos ou excluídos na pesquisa, nem mesmo uma razão explícita para tal. Nesse tipo de revisão, não há aderência a um protocolo prévio, nem uma estratégia de busca específica em bases de dados. Isso abre uma grande margem para o enviesamento dos estudos selecionados. Uma investigação que tem como objetivo avaliar a eficácia de uma psicoterapia necessita de um rigor maior - proporcionado por um delineamento diferente - para ser considerada confiável. Na falta de um método adequado, não podemos considerar tais estudos como suficientes para atestar a eficácia da terapia psicanalítica ou psicodinâmica, dada a necessidade de maior rigor e sistematização que a respectiva pergunta de pesquisa demanda empregar.

\section{Estudo Prospectivo/Quase-experimento}

Artigo considerado na seção: Huber et al., 2012.

Instrumento utilizado: Risk Of Bias In Non-randomised Studies of Interventions (ROBINS-I). 


\section{Huber et al., 2012}

Resultado da Análise: Risco de viés crítico.

\section{Discussão sobre o estudo}

O trabalho de Huber et al. (2012) é prospectivo, ou seja, selecionou participantes em um determinado período e acompanhou-os ao longo do tempo. $\mathrm{O}$ estudo é também quase-experimento, pois não foi realizada uma alocação aleatória dos pacientes entre os grupos de intervenção — o que dificulta a plena comparação e o estabelecimento de relações de causalidade entre tratamentos, especialmente com relação a estudos de intervenção propriamente randomizados. Como objetivo do estudo, Huber et al. (2012) buscam comparar, ao longo de três anos, os efeitos da Terapia Cognitivo-Comportamental (TCC), da Terapia Psicanalítica (TPN) e da Terapia Psicodinâmica (TPD) no tratamento de pacientes com diagnóstico primário de transtornos depressivos. Vale ressaltar que no estudo houve randomização dos dois grupos de TPN e TPD apenas, com posterior adição do grupo TCC (sem detalhamento). Além disso, os grupos de intervenção TPN e TPD não foram plenamente definidos, não havendo no texto uma explicitação da distinção entre os terapeutas das duas abordagens, ou mesmo dos tratamentos efetivamente realizados nos três grupos experimentais.

As principais medidas de resultado, utilizadas como forma de mensurar as possíveis melhorias promovidas pelos tratamentos, foram as seguintes: o alívio de sintomas foi avaliado utilizando o "Beck Depression Inventory" e o "Global Severity Index" (GSI) da "Symptom Check-List" (SCL-90-R). A melhora do funcionamento social-interpessoal foi avaliada com a versão alemã do "Inventory of Interpersonal Problems" (IIP) e o "Social Support Questionnaire" (F-SOZU short version); e, por fim, as mudanças de estruturas desadaptativas de personalidade, ou de autoesquema, foram avaliadas por meio do "INTREX Introject Questionnaire".

Ao avaliar a força das evidências fornecidas por um estudo, é prudente também verificar a existência de conflitos de interesse. A mera presença de conflitos não é suficiente para desconsiderarmos seus resultados, mas eles demandam que tenhamos um cuidado redobrado na avaliação do material, já que aumentam o risco de o estudo estar enviesado. No caso deste artigo, existem conflitos de interesse financeiros relevantes: o trabalho aqui analisado foi financiado pela Associação Psicanalítica Internacional e pela Fundação Dr. Zita und T. V. Steger para a Promoção da Psicanálise. Sem dúvidas, se um estudo é financiado por uma instituição que explicitamente visa a impulsão dos preceitos e práticas por ele investigados, ele é muito dado a ser influenciado para que dê resultados favoráveis esses preceitos e práticas, tal como podemos ver no caso supracitado do tabaco.

Além disso, uma leitura atenta encontra problemas metodológicos. Conforme declarado pelos autores, nesse estudo a duração média do Tratamento Psicanalítico (TPN) foi de 39 meses ou 234 sessões; do Tratamento Psicodinâmico (TPD) foi de 34 meses ou 88 sessões, e do Tratamento por Terapia Cognitivo-Comportamental (TCC) foi de 26 meses ou 45 sessões. É evidente como a gritante diferença entre o 
número de sessões dos diferentes tratamentos, que chega a ser 5 vezes maior se comparadas a TPN e a TCC, é uma variável confundidora que pode muito bem ser apontada como a real causa da diferença entre os desfechos dos tratamentos. Os próprios autores comentam na discussão como a desigualdade de dose entre os tratamentos pode explicar as diferenças em todas as dimensões do resultado.

Outro viés marcante do trabalho de Huber et al. (2012), que é justificado de forma incoerente pela limitação de recursos financeiros, diz respeito ao fato de que a alocação "randomizada" dos pacientes entre os grupos de tratamento teve início com a TPN e a TPD, para somente depois incluir a TCC. Acrescida à não manualização das abordagens terapêuticas, ressaltamos a presença de mais essa variável confundidora, que novamente pode beneficiar melhores desfechos para os Tratamentos Psicanalítico e Psicodinâmico. Considerando, portanto, os conflitos de interesse e graves problemas metodológicos do estudo, é inviável utilizá-lo de forma a sustentar com segurança conclusões comparando a eficácia terapêutica entre as abordagens.

\section{Avaliação de Qualidade (ROBINS-I)}

Mediante avaliação da qualidade metodológica pelo instrumento ROBINS-I, que avalia o risco de viés apresentado pelos procedimentos de condução do estudo reportados no trabalho, conclui-se que o estudo apresenta um risco de viés crítico. Dentre as possíveis classificações do ROBINS-I, essa é a mais baixa, o que compromete seriamente a utilidade dos achados relacionados aos efeitos das intervenções investigadas. Vale destacar ainda que informações essenciais - como datas e dados precisos sobre os períodos de avaliação/acompanhamento de cada grupo; definições ou descrições específicas dos procedimentos presentes nas sessões das intervenções conduzidas; presença/ausência de cointervenções; dados sobre os métodos e análises de pesquisa por meio de um registro, protocolo da pesquisa, dentre outras - não foram explicitamente incluídas no trabalho. Tudo isso poderia comprometer ainda mais sua qualidade metodológica, e ademais denota, por si só, um risco de viés e reduz gravemente a interpretabilidade e verificabilidade dos resultados apresentados. Confira os resultados na tabela 1.

\section{Ensaios Clínicos Randomizados}

Artigos considerados na seção: Fonagy et al., 2015; Knekt et al., 2016; Town et al., 2017. Instrumento utilizado: Segunda Versão do Cochrane risk-of-bias tool for randomized trials (RoB 2).

\section{Fonagy et al., 2015}

Resultado da Análise: Alto risco de viés.

\section{Discussão sobre o estudo}

Este ensaio clínico randomizado buscou avaliar a eficácia da terapia psicodinâmica de longa duração (LTPP) somada ao "tratamento padrão" (TAU) (o tratamento normalmente adotado no dia a dia, fora do âmbito de pesquisa) de acordo com as recomendações feitas pelo National Institute for Health and Care 
Excellence (2009) (NICE) (órgão do Reino Unido dedicado à saúde), e compará-la com os resultados que poderiam ser obtidos com 0 tratamento padrão isoladamente. A amostra do estudo consistiu de indivíduos diagnosticados com depressão maior de longa duração e que não tiveram boas respostas a pelo menos dois tipos de tratamentos oferecidos no passado.

Os autores obtiveram uma amostra de 129 sujeitos, dos quais 67 foram alocados para o grupo que receberia LTPP, sendo os outros 62 destinados ao grupo controle. Foram feitas avaliações com 0, 18, 24, 30 e 42 meses. Os resultados indicaram que, apesar das diferenças não serem significativas logo após o fim do tratamento com LTPP + TAU em comparação com TAU isoladamente, o primeiro grupo mostrava benefícios significativos (remissão parcial) após um tempo maior desde a finalização do tratamento, defendido como um "efeito atrasado" do tratamento. Os resultados foram avaliados principalmente utilizando a Hamilton Depression Rating Scale, e secundariamente com a Beck Depression Inventory - II, a Global Assessment of Functioning, a Clinical Outcomes in Routine Evaluation Outcome Measure e a Quality of Life Enjoyment and Satisfaction Questionnaire.

Nesse estudo, a definição de LTPP proposta pelos autores a classifica como sendo "psicanalítica", além de precisar durar mais de 18 meses. De acordo com Fonagy et al. (2015), todos os 22 terapeutas participantes eram certificados pelo British Psychoanalytic Council, e tinham em média 17,45 anos de experiência. De acordo com os autores, para realizar a comparação entre a LTPP + TAU vs o TAU isolado, os tratamentos psicoterápicos de curta duração considerados como TAU pelo NICE não foram permitidos no grupo de LTPP. Isso significaria que o primeiro grupo recebeu a LTPP sempre somada a outros tratamentos reconhecidos, exceto no caso em que esses fossem psicoterapias de curta duração, para ser comparada ao grupo controle de TAU isolado. Durante o período de intervenção, apenas $1,5 \%$ do grupo de LTPP e 19,4\% do grupo controle receberam intervenções com CBT; já no período pós-intervenção, essas proporções passaram para 10,5\% e 8,1\%, respectivamente.

O primeiro grupo, de LTPP, recebeu em média 41 horas de tratamento, enquanto o grupo controle recebeu apenas 11 horas. Isso é apontado pelos próprios autores (Fonagy et al., 2015) como uma possível causa dos diferentes resultados observados, além da diferença da intensidade e qualidade dos tratamentos ofertados. Havia uma diferença socioeconômica também entre os grupos, tendo o grupo de LTPP + TAU maior escolaridade e melhor índice de emprego, mas os autores afirmaram terem ajustado para esse fator em sua análise. Houve também um auxílio financeiro por parte da International Psychoanalytic Association, o que pode se caracterizar como um conflito de interesses financeiro.

\section{Avaliação de Qualidade (ROB 2)}

A avaliação da qualidade metodológica deste estudo, realizada por meio do instrumento RoB 2, teve como conclusão a asseveração de um alto risco de viés, ou seja, a classificação mais baixa de acordo com 0 instrumento. Mais especificamente, o domínio mais desfavorável diz respeito à insuficiência de dados 
de resultado, o que compromete a interpretação dos achados e impede que possamos tratá-los como boas evidências. Confira os resultados completos na tabela 2.

\section{Knekt et al., 2016}

Resultado da Análise: Alto risco de viés.

\section{Discussão sobre o estudo}

Esse estudo pretendeu fornecer informações de natureza comparativa entre os efeitos e a persistência dos resultados de Terapias Psicodinâmicas de Longo Prazo (LPP), Terapias Focadas de Curta Duração (STF) e Terapias Psicodinâmicas de Curta Duração (SPP). Para isso, pacientes ambulatoriais de serviços psiquiátricos, da região de Helsinque (Finlândia), receberam um acompanhamento de 10 anos de duração. A amostra, com um total de 326 participantes, era composta por pacientes com transtornos depressivos ou de ansiedade que causavam disfunção no trabalho. Os investigadores basearam-se em questionários de autorrelato para aferir as medidas de desfecho selecionadas para o estudo, quais sejam: os sintomas psiquiátricos, a capacidade para o trabalho, personalidade, funcionamento social, necessidade de tratamento e remissão. Para realizar a avaliação dessas categorias, os pesquisadores empregaram os seguintes instrumentos:

- o Symptom Check List (SCL-90) para os sintomas psiquiátricos e para a remissão de sintomas;

- o work subscale of the Social Adjustment Scale (SAS-SR) para a capacidade de trabalhar;

- o instrumento SAS-SR e o Sense of Coherence Scale para o funcionamento social;

- e finalmente, para as medidas de personalidade, usou-se o self-concept questionnaire of the Structural Analysis of Social Behavior, o Defense Style Questionnaire e o Inventory of Interpersonal Problems.

Entrevistas telefônicas, questionários e registros de saúde serviram para o acompanhamento dos pacientes.

Os resultados indicaram que, comparativamente à SPP, a LPP demonstrou maiores reduções nos sintomas, maior índice de melhora para a capacidade de trabalho e maiores taxas de remissão. A prevalência de tratamentos auxiliares também alcançou porcentagens significativas, sendo: $47 \%$ na SFT, $58 \%$ na SPP e $33 \%$ na LPP. Com isso, os autores coligiram que, ao fim do acompanhamento, os benefícios da LPP em comparação com as terapias de curto prazo são pequenos, embora significativos em sintomas e capacidade de trabalho.

\section{Avaliação de Qualidade (ROB 2)}

A avaliação da qualidade metodológica deste trabalho teve como conclusão a asseveração de um alto risco de viés (a classificação mais baixa pelo RoB 2), com 
direção prevista favorecendo o grupo experimental LPP. Notadamente, o estudo obteve resultados desfavoráveis em vários domínios do instrumento RoB 2. Há alto risco de viés devido a desvios das intervenções pretendidas (analisando-se o efeito de aderir à intervenção), insuficiência de dados de resultado, e problemas na mensuração e seleção do resultado apresentado. Confira os resultados completos na tabela 2.

\section{Town et al., 2017}

Resultado da Análise: Alto risco de viés.

\section{Discussão sobre o estudo}

Este ensaio clínico investiga a eficácia da Psicoterapia Dinâmica Intensiva de Curto Prazo (ISTDP) para o tratamento da depressão resistente ao tratamento (TRD), em comparação aos cuidados das equipes de saúde mental comunitárias de atenção secundária (CMHTs) que serviram como grupo controle (recebendo o tratamento padrão - TAU). Um total de 60 pacientes ambulatoriais foram selecionados para o estudo, possuindo diagnóstico primário de Transtorno Depressivo Maior conforme os critérios do DSM-IV. Respondendo aos objetivos do trabalho, os autores convencionaram um formato de atendimento com limite de 20 sessões. Os grupos controle receberam a abordagem de uma equipe multidisciplinar, dentro da qual estavam incluídas farmacoterapia, gestão clínica, atividades de suporte ou estruturadas e focadas em gestão de sintomas, e psicoterapia individual ou em grupo. Os resultados favoreceram a ISTDP a despeito do TAU, indicando que os seus efeitos ao longo do tempo são estatisticamente significativos. A medição principal dos resultados se deu através da Hamilton Depression Rating Scale (HAM-D), e a medida secundária decorreu pela aplicação do Patient Health Questionnaire-9 (PHQ-9).

\section{Avaliação de Qualidade (ROB 2)}

A avaliação da qualidade metodológica deste estudo também indica um alto risco de viés, a classificação mais baixa pelo RoB 2. O domínio mais desfavorável, segundo a análise pelo instrumento, é de dados de resultados faltantes, que podem levar a problemas incontornáveis na interpretação da conclusão final. Confira os resultados completos na tabela 2 .

\section{Revisões Sistemáticas}

Artigos considerados na seção: Leichsenring \& Klein, 2014; Leichsenring et al., 2015. Instrumento: A MeaSurement Tool to Assess systematic Reviews 2 (AMSTAR-2)

\section{Leichsenring \& Klein, 2014}

Resultado da Análise: Nível de confiança nos resultados criticamente baixo.

\section{Discussão sobre o estudo}


Neste estudo, Leichsenring e Klein buscaram discutir as evidências para a psicoterapia psicodinâmica (PDT) para transtornos mentais específicos. Este artigo é muito similar ao de Leichsenring et al. (2015) (ver nesta seção, logo abaixo), mencionando os critérios para classificar um tratamento empiricamente sustentado propostos por Chambless e Hollon (1998). Os autores tentam concluir que a PDT atende aos seus critérios. Isso cria um questionamento sobre se essas publicações (Leichsenring \& Klein, 2014; Leichsenring et al., 2015) não podem ser classificadas como redundantes (o mesmo ocorre com outras metanálises de Leichsenring, veja na próxima seção). Além disso, era um dos critérios que as terapias incluídas nos artigos selecionados fossem manualizadas para inclusão neste trabalho, o que coloca em questão a não representatividade da psicanálise, já que muitos de seus adeptos não consideram pertinente uma psicanálise manualizada, como discute Dunker (2021).

\section{Avaliação de Qualidade (AMSTAR 2)}

A despeito da abrangência do trabalho, a revisão falhou em absolutamente todos os critérios de qualidade estipulados pelo AMSTAR 2 para o delineamento de revisões sistemáticas. Não houve aderência adequada à estratégia PICO, nem um registro de protocolo da pesquisa anterior à publicação do estudo. Também não houve uma justificativa para os delineamentos incluídos no estudo, e que foi apresentada era contraditória com a escolha feita de fato. Tentaram justificar que tanto RCT's quanto observacionais são importantes, mas incluíram apenas RCT's. A estratégia de busca para a seleção de estudos foi inadequada. Foram Ignorados passos tais como a consulta de publicações em diferentes idiomas, a verificação da literatura cinzenta (publicações relevantes, mas que foram publicadas fora do meio acadêmico convencional; por ex: dados disponíveis em sites de organizações, documentos governamentais, preprints, teses e outros) e registros de estudos/protocolos. A seleção dos estudos e extração dos dados não foram feitas de forma pareada e independente, afinal nem mesmo foi mencionada. As fontes de financiamentos dos estudos individuais não foram listadas, e os conflitos de interesse dos autores do próprio artigo não foram declarados. A origem da heterogeneidade também não foi discutida. Uma lista completa de artigos excluídos também não foi apresentada ao leitor, tampouco uma justificativa para a exclusão. Os estudos incluídos não foram adequadamente descritos, faltando uma descrição adequada dos resultados (outcomes) e o detalhamento da população, intervenção, comparadores e dados consistentes para o follow-up. Não foi feita uma análise de risco de viés dos estudos individuais. Na verdade, a palavra viés nem sequer aparece ao longo das 31 páginas do trabalho. Os vieses de estudos individuais não foram levados em conta na discussão e interpretação dos resultados. Por fim, o conjunto de suas características classifica a confiabilidade da pesquisa de Leichsenring e Klein (2014) como criticamente baixa. Confira os resultados completos na tabela 3 .

\section{Leichsenring et al., 2015}

Resultado da Análise: Nível de confiança nos resultados criticamente baixo. 


\section{Discussão sobre o estudo}

Este estudo buscou fazer o mesmo que já havia sido feito em Leichsenring \& Klein (2014): Leichsenring et al. (2015) buscaram discutir sobre as evidências para a psicoterapia psicodinâmica (PDT) para transtornos específicos, utilizando o critério de Chambless e de Hollon, proposto em 1998. Em seu artigo, Leichsenring et al. (2015) focaram em buscar RCT's que utilizavam manuais de tratamento ou similares que estivessem de acordo com os critérios de 1998. Em resumo, a proposta original de Chambless e Hollon, resumida por Tolin et al. (2015), define que para um tratamento ser considerado empiricamente sustentado (TES) deve haver: (a) pelo menos dois estudos (de preferência, RCT's) feitos por grupos de pesquisa independentes e bem planejados ou (b) uma grande série de estudos controlados e bem planejados de delineamento de sujeito único. Para ser considerado "provavelmente eficaz", apenas um exemplar de (a) ou uma pequena série de (b) seriam suficientes (para ver a proposta completa, checar a p. 18 de Chamblees \& Hollon, 1998). É interessante notar que segundo a definição também é necessário que o tratamento seja guiado por manuais, o que já coloca de antemão uma diferença importante entre a prática psicanalítica e as terapias avaliadas por esses estudos, o que é discutido por Dunker (2021).

Após o artigo de Chambless e Hollon, foi feita uma atualização por parte de Tolin et al. (2015), que saiu no mesmo ano que o artigo de Leichsenring et al (2015). Essa atualização foi motivada pelo fato de o critério anterior já se mostrar ultrapassado e obsoleto (Tolin et al., 2015). A definição de "tratamento empiricamente sustentado" proposto por Chambless e Hollon (1998) recebeu críticas significativas. Alguns exemplos são "definir um padrão inaceitavelmente baixo para eficácia" (Tolin et al., 2015, p. 320) ao colocar apenas dois estudos como critério suficiente, e também não dar a atenção necessária a publicações de resultados negativos (para conferir mais críticas, verifique o artigo de Tolin et al., 2015). Como os autores explicam:

Por exemplo, se dois estudos encontraram evidências de que um determinado tratamento é eficaz, cinco estudos descobriram que o tratamento não é melhor do que o placebo, e dez estudos descobriram que o tratamento é pior do que o placebo, os critérios atuais para uma designação de um TSE seriam satisfeitos (Tolin et al., 2015, p. 320) [tradução nossa].

Esse exemplo é um problema ao qual o próprio artigo de Leichsenring et al. (2015) está sujeito: os autores colocaram como critério de inclusão que os estudos considerados mostrassem resultados positivos a favor da PDT, não considerando então aqueles que poderiam demonstrar resultados desfavoráveis. Isso teria grande potencial de enviesar as conclusões tiradas, e diversos tratamentos avaliados por Leichsenring et al. (2015) foram neste trabalho considerados como terapias empiricamente sustentadas (TSE's) ou provavelmente eficazes mesmo tendo um número muito pequeno (como 3, 2 ou 1) de RCT's disponíveis. Leichsenring et al. (2015) também propuseram em seu próprio artigo uma atualização do critério anterior no que diz respeito ao poder estatístico e tamanho amostral por grupos ativos do estudo, sugerindo que cada grupo deveria passar a ter 70 sujeitos em vez 
de 25-30. Entretanto, nos estudos que eles mesmos incluíram, diversos deles têm um tamanho amostral bem menor do que o proposto (para ambos os critérios).

A proposta atualizada feita por Tolin et al. (2015) é de que, ao invés de utilizarmos apenas a existência de dois estudos como parâmetro, levemos em conta as revisões sistemáticas da literatura, ao mesmo tempo que avaliamos seu risco de viés e qualidade das evidências apresentadas. A proposta contemporânea está mais focada na totalidade das evidências disponíveis na literatura, em vez de um pequeno conjunto de dois estudos. Isso acaba por tornar o estudo de Leichsenring et al. (2015) desatualizado, por utilizar um critério obsoleto para avaliar se a PDT realmente é eficaz para transtornos específicos.

\section{Avaliação de Qualidade (AMSTAR 2)}

Embora tenha apresentado conclusões extremamente otimistas acerca dessas intervenções, o estudo aqui analisado falhou em quatro itens críticos de qualidade do AMSTAR 2, além de outros seis não-críticos. Não houve aderência adequada à estratégia PICO. Não houve registro de protocolo da pesquisa anterior à publicação do estudo. A estratégia de busca para a seleção de estudos foi inadequada. Não se discutiram restrições a respeito da busca por artigos de diferentes idiomas, verificação da literatura cinzenta e registros de estudos/protocolos. A seleção dos estudos foi descrita de forma ambígua. Apesar de terem dito que foi independente, não mencionaram ter alcançado consenso. A extração dos estudos não foi feita de forma pareada e independente. Os estudos incluídos não foram adequadamente descritos, faltando uma descrição adequada dos resultados (outcomes) e o detalhamento da população, comparadores, setting do estudo e dados consistentes para o follow-up. Não foi feita uma análise de risco de viés dos estudos individuais. Aliás, o termo "viés" nem mesmo é mencionado no trabalho. As fontes de financiamento dos estudos individuais não foram reportadas. Os vieses de estudos individuais não foram levados em conta na discussão e interpretação dos resultados. A origem da heterogeneidade não foi discutida. Em virtude das características aqui apresentadas, o trabalho de Leichsenring et al. (2015) possui confiabilidade criticamente baixa. Confira os resultados completos na tabela 3.

\section{Metanálises}

Artigos considerados na seção: Leichsenring et al., 2004; Leichsenring \& Rabung, 2008; Driessen et al., 2010; Leichsenring \& Rabung, 2011b; Smit et al., 2012; Abbass et al., 2014.

Instrumento: A MeaSurement Tool to Assess systematic Reviews (AMSTAR-2)

\section{Leichsenring et al., 2004}

Resultado da Análise: Nível de confiança nos resultados criticamente baixo.

\section{Discussão sobre o estudo}

Neste estudo, Leichsenring et al. (2004) realizaram uma metanálise de 17 estudos de psicoterapia psicodinâmica de curta duração (STPP), buscando avaliar 
sua eficácia para transtornos psiquiátricos. Relataram como resultados a obtenção de indicadores favoráveis para a diminuição de sintomas psiquiátricos em geral, a melhora do funcionamento social e dos sintomas problemáticos. Bhar \& Beck (2009), posteriormente, realizaram uma crítica ao trabalho. Eles buscaram avaliar a integridade do tratamento de seus 9 melhores estudos individuais. A integridade do tratamento é um conceito que diz respeito a se um tratamento foi aplicado da maneira como tinha por objetivo ser aplicado, tendo relação com a adesão do terapeuta aos protocolos, competências, habilidades e diferenças com outros tratamentos. Se uma pesquisa não possui uma boa integridade dos tratamentos avaliados, a possibilidade de concluir algo sobre sua eficácia ou superioridade em relação a outros é consideravelmente prejudicada (Bhar \& Beck, 2009). Utilizando-se da Implementation of Treatment Integrity Procedures Scale (ITIPS), os autores avaliaram os quatro domínios da integridade do tratamento, obtendo como resultado a constatação de que nenhum dos estudos incluídos foi capaz de atender de forma adequada a todos eles.

Também, a metanálise concluiu que a terapia psicodinâmica era eficaz principalmente porque se calculou o tamanho do efeito dessas intervenções a partir da diferença entre a linha de base e os desfechos dos pacientes a ela submetidos no fim do estudo. Um procedimento mais adequado seria calcular o tamanho do efeito das intervenções psicodinâmicas em relação ao tratamento padrão/lista de espera ou outras intervenções ativas.

\section{Avaliação de Qualidade (AMSTAR 2)}

Este estudo falhou em todos os sete itens críticos do AMSTAR 2 como determinantes da qualidade de uma metanálise, além de outros sete não críticos. Não houve registro de protocolo da pesquisa anterior à publicação do estudo. A estratégia de busca para a seleção de estudos foi inadequada, já que não se discutiu restrições a respeito da busca por artigos de diferentes idiomas, investigação das listas de referência dos artigos incluídos, verificação da literatura cinzenta, consulta a experts do campo e registros de estudos/protocolos. A seleção dos estudos e extração dos dados não foi feita de forma independente e pareada, já que o segundo revisor da extração apenas checou mas não fez a extração também. Uma lista completa de artigos excluídos também não foi apresentada ao leitor, tampouco uma justificativa para a exclusão, de maneira que não foi possível determinar se a eles de fato se aplicam às justificativas para exclusão. Os estudos incluídos não foram adequadamente descritos, faltando uma descrição adequada da população e o seu detalhamento, bem como detalhamento dos comparadores, o setting do estudo e dados consistentes para o follow-up. Não foi feita uma análise de risco de viés dos estudos individuais, o impacto dos vieses não foi levado em consideração nos resultados da metanálise e na síntese das evidências, e os vieses de estudos individuais não foram levados em conta na discussão e interpretação dos resultados. A combinação dos resultados estatísticos em metanálise não foi justificada nem adequada. A origem da heterogeneidade não foi discutida, nem 
possíveis vieses de publicação. Os conflitos de interesse dos próprios autores não foram declarados, e as fontes de financiamento dos estudos individuais não foram reportadas. Por essas razões, a confiabilidade das conclusões do estudo de Leichsenring et al. (2004) é criticamente baixa. Confira os resultados completos na tabela 3.

\section{Leichsenring \& Rabung, 2008}

Resultado da Análise: Nível de confiança nos resultados criticamente baixo.

\section{Discussão sobre o estudo}

A metanálise de Leichsenring e Rabung (2008), publicada no JAMA, é um dos trabalhos mais citados dentre aqueles que buscam avaliar a eficácia de psicoterapias psicodinâmicas de longa duração (LTPP). Entretanto, também é um grande exemplo de por que impacto não é sinônimo de qualidade ou cientificidade. Esta metanálise já sofreu um número enorme de críticas, sobre as quais podemos começar citando o trabalho de Littell e Shlonsky (2010): os autores buscaram fazer uma avaliação da qualidade metodológica desta famosa metanálise, utilizando a ferramenta AMSTAR, que é a versão mais antiga do instrumento que utilizamos na nossa avaliação (AMSTAR 2). A primeira versão do AMSTAR é constituída de 11 perguntas, que incluem as características do design do estudo, a metodologia utilizada na coleta e busca de artigos, a caracterização e avaliação dos estudos incluídos, a declaração de conflito de interesses, dentre outros. No caso da metanálise de Leichsenring e Rabung, ela não foi capaz de cumprir nem mesmo um único critério do AMSTAR. Ainda assim, falhando em cumprir todos os critérios de qualidade estipulados para uma investigação do tipo, é tratada por Dunker (2021) como uma "prova cabal" da eficácia da LTPP (ou, pior ainda: da psicanálise como um todo!).

Para avaliarmos se uma metanálise tem qualidade, as características de seus estudos individuais são cruciais. Bhar et al. (2010) fizeram uma análise sobre os estudos que buscavam fazer comparações com outros tipos de tratamento incluídos nesta metanálise: os oito estudos tinham um número muito pequeno de participantes, abrindo margem para a superestimação de tamanhos de efeito devido a vieses de publicação (Bhar et al., 2010). Isso, de acordo com Bhar et al. (2010), garantiria que um efeito supostamente grande fosse apresentado mesmo no caso em que a terapia em si não fosse realmente efetiva. Também em relação aos estudos em particular, em apenas dois dos oito estudos era possível identificar de maneira clara os métodos de randomização e apenas um tinha baixo risco de viés (Bhar et al., 2010) (e adicionalmente as suas condições de ocultação de alocação e cegagem eram ou inconsistentes, ou inadequadas (Pignotti e Albright, 2010)). Além disso, foram observados indícios de uma exclusão arbitrária de um estudo que não favorecia a psicoterapia psicodinâmica de longa duração, apontada por Beck e Bhar (2009) e por Roepke e Renneberg (2009).

Bhar et al. (2010) também apontam que as condições controle selecionadas na metanálise, chamadas pelos autores de "métodos de psicoterapia de curta 
duração", incluíam diversos tratamentos que não possuíam sustentação empírica, ou que nem mesmo eram psicoterapias, como por exemplo: aconselhamento nutricional, lista de espera, tratamento psiquiátrico padrão, fornecimento do número de telefone de um terapeuta, dentre outros. Isso não os impediu de afirmar que seus resultados provaram que a psicoterapia psicodinâmica de longa duração era superior a outras "psicoterapias de curta duração".

De acordo com Bhar et al., (2010), apenas dois estudos faziam uma comparação com psicoterapias empiricamente sustentadas para o respectivo transtorno que visavam tratar, tornando as comparações entre LTPP e psicoterapias de curto prazo injustas. Nos estudos incluídos, a psicoterapia psicodinâmica de longa duração só mostrou superioridade ao seu concorrente quando este era um tratamento invalidado, ou quando não envolvia psicoterapia (Bhar et al., 2010). A metanálise compara 1053 pacientes recebendo LTPP, tendo como controle apenas 257 outros, e destes apenas 36 receberam uma terapia empiricamente sustentada para a condição que o estudo propunha investigar (Coyne, 2014). Além disso o tratamento avaliado (LTPP) oferecia em média 102 sessões por paciente, enquanto os controles ofereciam apenas 33 (Bhar et al., 2010); uma diferença discrepante. A mistura que Leichsenring e Rabung (2008) estariam fazendo nessa situação, entre terapias que não tinham suporte empírico com terapias que tinham, como brincam Pignotti e Albright (2010), é como comparar maçãs com laranjas.

Além disso, Bhar et al. (2010) apontam que Leichsenring e Rabung (2008) também apresentaram tamanhos de efeito implausíveis, "estatisticamente impossíveis" (Thombs et al., 2009, p. 930) e partindo de "cálculos grosseiramente errados" (Bhar et al., 2010, p. 209) (um tamanho de efeito, à propósito, é um valor que busca avaliar qual a força da relação entre duas variáveis; é uma resposta para a pergunta: se a terapia funciona, funciona com efeitos pequenos? grandes? moderados?). Os procedimentos adotados pelos autores para a análise dos estudos acabou por anular os efeitos da randomização dos RCT's, transformando esses estudos em observacionais e tirando sua capacidade de apontar relações causais (Kriston et al., 2009; Littell \& Shlonsky, 2010).

Apesar de alguns proponentes da psicanálise criticarem o uso de manuais diagnósticos, assim como o próprio Dunker (2021) o fez em seu vídeo, 7 dos 8 estudos de Leichsenring e Rabung (2008) usavam manuais ou protocolos de manuais (Bhar et al., 2010), o que mostra uma diferença importante entre o que (pelo menos alguns) psicanalistas pregam como demandas teóricas e o que estão dispostos a aturar quando pressionados a defender empiricamente as suas alegações. Afirmar que "todas as psicanálises se ajustam" nos estudos de terapia psicodinâmica, como Dunker (2021) afirmou, se mostra um erro, conforme exposto aqui.

Leichsenring e Rabung (2011a) escreveram uma resposta às críticas de Bhar et al. (2010), tentando comparar sua metanálise com estudos de terapia cognitivo-comportamental (CBT). Seu principal argumento consistiu em tentar mostrar que estudos de CBT também falham em critérios de qualidade, assim como a sua própria metanálise foi acusada de falhar. Assim, Bhar et al. são criticados por 
terem feito uma análise crítica da metanálise do Leichsenring e Rabung, mas não terem feito o mesmo com estudos de CBT. Entretanto, esse argumento não procede, pois independente de ser verdadeiro ou falso que estudos de outras psicoterapias têm vieses consideráveis, isso não significa que eles podem simplesmente ignorar os graves problemas de seu próprio estudo (a famosa falácia tu quoque). Não é porque outros estudos também podem ser ruins que a má qualidade metodológica deve ser perdoada e amplamente aceita. Coyne et al. (2011) posteriormente também publicaram uma tréplica aos outros apontamentos dos autores.

\section{Avaliação de Qualidade (AMSTAR 2)}

Este estudo também cometeu todas as sete falhas críticas para uma metanálise estabelecidas pelo AMSTAR 2, além de outras cinco não críticas. Não houve registro de protocolo da pesquisa anterior à publicação do estudo. A estratégia de busca para a seleção de estudos foi inadequada, já que não se discutiu restrições a respeito da busca por artigos de diferentes idiomas, investigação das listas de referência dos artigos incluídos, verificação da literatura cinzenta e registros de estudos/protocolos. A seleção dos estudos não foi feita de maneira pareada e independente, e isso nem mesmo foi mencionado. Uma lista completa de artigos excluídos também não foi apresentada ao leitor, tampouco uma justificativa para a exclusão. Descreveram apenas parcialmente os estudos incluídos, faltando detalhes sobre a população, intervenção, comparadores, setting e dados para avaliar o follow-up. Não foi feita uma análise de risco de viés dos estudos individuais. Vale apontar que o instrumento utilizado pelos autores para acessar a qualidade dos estudos (escala Jadad) na verdade se destina a verificar quão compreensivos são os dados reportados por uma pesquisa. $O$ instrumento nem sequer avalia, por exemplo, se os estudos observaram o sigilo de alocação (o cuidado para que nem os participantes, nem os pesquisadores saibam quais sujeitos foram para quais braços da pesquisa). As fontes de financiamento dos estudos individuais não foram reportadas, e os conflitos de interesse não foram declarados (declaração de financiamento não é idêntico a conflito de interesses). Os métodos estatísticos usados para combinar os estudos em metanálises não foram adequados nem justificados. Estudos com diagnósticos, condições de controle e desfechos muito diferentes tiveram estimativas de efeito agrupadas, o que compromete a sua representatividade em relação aos estudos individuais. Vale lembrar que, embora ele tenha a pretensão de avaliar a eficácia da Psicoterapia Psicodinâmica de Longo Prazo (LTTP), os autores combinaram estudos observacionais com RCT's. O impacto dos vieses não foi levado em consideração nos resultados da metanálise e na síntese das evidências, nem na discussão e interpretação dos resultados. Possíveis vieses de publicação não foram investigados ou discutidos de forma adequada (fail safe-n não é adequado, de acordo com Higgins et al. (2011c)). A origem da heterogeneidade não foi discutida; os artigos incluídos apresentam uma marcante heterogeneidade clínica, mas isso também não foi abordado e discutido pelos autores. Por essas razões, a 
confiabilidade das conclusões do estudo de Leichsenring e Rabung (2008) é criticamente baixa. Confira os resultados completos na tabela 3 .

\section{Driessen et al., 2010}

Resultado da Análise: Nível de confiança nos resultados criticamente baixo.

\section{Discussão sobre o estudo}

Driessen et al., (2010) realizaram uma metanálise para avaliar se a psicoterapia psicodinâmica de curta duração (STPP) era um tratamento eficaz para depressão. 23 estudos foram incluídos, tanto RCT's quanto estudos não controlados e não randomizados. Os autores consideraram estudos que fizeram comparações com outras psicoterapias, o tratamento usual (TAU) e listas de espera, bem como estudos que não tinham grupo controle, o que pode ser um grande problema para estimar os reais resultados da STPP. Os estudos incluídos, em geral, não apresentavam boa qualidade metodológica, e muitos possuíam um tamanho amostral pequeno, o que é admitido pelos próprios autores (Driessen et al., 2010).

\section{Avaliação de Qualidade (AMSTAR 2)}

Dos sete domínios críticos elegidos pelo AMSTAR 2 como fundamentais para a qualidade de uma metanálise, o trabalho desenvolvido por Driessen et al. (2010) falhou em todos, além de outros 6 não críticos. Não houve registro de protocolo da pesquisa anterior à publicação do estudo, nem a apresentação de uma justificativa adequada para os delineamentos incluídos. A estratégia de busca para a seleção de estudos estava incompleta, pois não reportou os anos referentes à busca dos artigos. A extração dos estudos não foi feita de forma pareada e independente, nem mesmo sendo mencionada. Uma lista completa de artigos excluídos também não foi apresentada ao leitor, tampouco uma justificativa para a exclusão; Apenas artigos em específico foram discutidos, mas a lista completa de todos os lidos em full-text não foi fornecida. Não foi feita uma análise de risco de viés dos estudos individuais, o impacto dos vieses não foi levado em consideração nos resultados da metanálise e na síntese das evidências, os vieses de estudos individuais não foram levados em conta na discussão e interpretação dos resultados e possíveis vieses de publicação não foram investigados adequadamente (os autores utilizaram o método trim and fill, que não é recomendado pela Cochrane (Higgins \& Green, 2011a)). As fontes de financiamento dos estudos individuais não foram reportadas, e os conflitos de interesse dos próprios autores não foram declarados. A combinação dos resultados estatísticos em metanálises não foi justificada e a origem heterogeneidade não foi discutida. Em virtude dessas razões, de acordo com o AMSTAR 2, a classificação da confiabilidade dos resultados da metanálise de Driessen et al. (2010) é criticamente baixa. Confira os resultados completos na tabela 3 .

\section{Leichsenring \& Rabung, 2011b}

Resultado da Análise: Nível de confiança nos resultados criticamente baixo. 


\section{Discussão sobre o estudo}

Esta metanálise foi colocada como se fosse uma atualização, por parte de Leichsenring e Rabung, da sua publicação mais famosa de 2008. Entretanto, Coyne $(2011 ; 2014 ; 2016)$ a acusou de ser redundante, pois incluiu apenas um único novo estudo que não estava presente na metanálise anterior. A única nova inclusão era irrelevante para avaliar a LTPP, haja vista que a terapia controle não é empiricamente sustentada nem manualizada, e poderia ter sido incluída desde antes na metanálise original publicada no JAMA, já que o estudo era mais antigo (Coyne, 2011; 2014; 2016).

Novamente, de acordo com Coyne (2011), a nova metanálise voltou a pecar em vários sentidos: não foi oferecida uma lista de estudos excluídos; houve a inclusão de estudos com baixa qualidade metodológica, com risco considerável de viés e com um tamanho amostral muito pequeno; havia evidências de cherry picking (seleção daquilo que é mais conveniente); e novamente houve comparações de controle injustas, já que as terapias com mais alto grau de evidências acabavam por não ser incluídas. Isso impede que a conclusão de que a LTPP é superior a terapias de curta duração proceda, e não constitui evidência suficiente a favor da LTPP.

\section{Avaliação de Qualidade (AMSTAR 2)}

Esta metanálise é uma atualização do trabalho publicado pelos mesmos autores em 2008. O estudo falhou em 6 itens críticos e sete não críticos. Não houve aderência adequada à estratégia PICO, pois falhou em apontar os outcomes. Não houve registro de protocolo da pesquisa anterior à publicação do estudo. Também não houve uma justificativa adequada para a escolha dos delineamentos incluídos no estudo. A estratégia de busca para a seleção de estudos foi inadequada, já que não se explicitaram restrições referentes a diferentes idiomas, registros de estudos/protocolos e faltou verificação da literatura cinzenta. A seleção dos estudos não foi feita de forma pareada e independente, e nem mesmo mencionada. Uma lista completa de artigos excluídos também não foi apresentada ao leitor. Os estudos incluídos foram apenas parcialmente bem descritos, faltando uma descrição mais profunda da população, dos comparadores, o setting do estudo e dados consistentes para o follow-up. Não foi feita uma análise de risco de viés dos estudos individuais, o impacto dos vieses não foi levado em consideração nos resultados da metanálise e na síntese das evidências, e os vieses de estudos individuais não foram levados em conta na discussão e interpretação dos resultados. As fontes de financiamento dos estudos individuais não foram reportadas. A combinação dos resultados estatísticos em metanálise não foi justificada, e a origem da heterogeneidade não foi discutida. Em virtude disso, a confiabilidade das conclusões do artigo de Leichsenring e Rabung (2011b) também é criticamente baixa. Confira os resultados completos na tabela 3.

\section{Smit et al. (2012)}


Resultado da Análise: Nível de confiança nos resultados criticamente baixo.

\section{Discussão sobre o estudo}

O artigo de 2013 de Leichsenring et al. é uma crítica à metanálise de Smit et al. (2012), que também buscou avaliar a eficácia da LTPP. Os autores (Smit et al., 2012) chegaram a comentar que fizeram também uma busca extensa por ensaios clínicos randomizados de psicanálise, mas não conseguiram achar nenhum, o que restringiu a análise à LTPP, já que não há como fazer uma metanálise sem estudos publicados. Novamente, isso retoma a crítica de que não podemos afirmar que "todas as psicanálise se encaixam" nesses estudos levantados para defendê-la; pelo contrário: parece que os RCT's que avaliam a psicanálise propriamente dita (e não as terapias psicodinâmicas) não podem nem mesmo ser encontrados na literatura científica com facilidade, mesmo na intenção de se realizar uma revisão.

Também, ao contrário de todos os outros estudos incluídos na lista de Dunker (2021), este é o único que não reporta resultados superiores para as terapias psicodinâmicas; pelo contrário, tenta defender que os resultados indicam que a LTPP tem eficácia equivalente aos controles, dispondo de evidências limitadas e conflitantes.

\section{Avaliação de Qualidade (AMSTAR 2)}

Este estudo apresentou cinco falhas metodológicas críticas de acordo com os critérios do AMSTAR 2, bem como cinco não críticas.Não houve registro de protocolo da pesquisa anterior à publicação do estudo. A extração dos estudos não foi feita de forma pareadas e independente, já que o segundo revisor apenas checou mas não fez a extração também. Uma lista completa de artigos excluídos também não foi apresentada ao leitor, tampouco uma justificativa para a exclusão. Os estudos incluídos foram apenas parcialmente bem descritos, faltando uma descrição mais detalhada da população, dos comparadores e do setting. A análise de risco de viés dos estudos individuais foi apenas parcialmente adequada, o impacto dos vieses não foi levado em consideração nos resultados da metanálise e na síntese das evidências, e possíveis vieses de publicação não foram investigados ou discutidos. As fontes de financiamento dos estudos individuais não foram reportadas, e não foi reportado como os autores manejaram seus conflitos de interesse (apesar de ter sido declarada fonte de financiamento). Os métodos estatísticos usados para combinar os estudos não foram justificados. Dessa maneira, pelas razões expostas, a metanálise de Smit et al. (2012) possui confiabilidade criticamente baixa. Confira os resultados completos na tabela 3.

\section{Abbass et al., 2014}

Resultado da Análise: Nível de confiança nos resultados criticamente baixo.

\section{Discussão sobre o estudo}

Como já foi mencionado, na lista original Dunker (2021) citou a versão de 2006 dessa metanálise. Entretanto, quanto mais antiga uma metanálise é, mais 
desatualizada acaba se tornando, já que novos estudos podem ter sido publicados e não estariam sendo considerados. Para minimizar esse problema, e avaliar as evidências mais recentes sobre a STPP, decidimos fazer uma avaliação da segunda e mais recente versão do artigo, publicada em 2014.

Esse estudo buscou avaliar a eficácia da psicoterapia psicodinâmica de curta duração (STPP) para transtornos mentais comuns, incluindo transtornos depressivos não bipolares, transtornos de ansiedade e transtornos somatoformes. Houve uma maior transparência em relação aos procedimentos adotados nesse trabalho, em comparação aos outros estudos similares mais problemáticos, como os de Leichsenring. Além disso, esse foi o único de todos os estudos avaliados que apresentou um protocolo pré-registrado do que os pesquisadores tinham por objetivo e planejamento. Entretanto, os estudos incluídos tinham qualidade variada, incluindo RCT's com alto risco de viés. Havia considerável heterogeneidade e grupos com um tamanho amostral demasiadamente pequeno. Apesar dos resultados mostrarem melhorias variando de modestas a grandes por parte da STPP em relação a tratamentos controle, os próprios autores sugerem cautela na interpretação desses resultados, devido a tais limitações.

\section{Avaliação de Qualidade (AMSTAR 2)}

Esta metanálise é o trabalho que falhou no menor número de itens entre todos avaliados até aqui. Ainda assim, falhou em quatro dos sete itens críticos do AMSTAR 2, além de outros quatro não críticos. Houve alguns desvios do protocolo do estudo, em especial relativos à estratégia de busca. Não houve uma justificativa para os delineamentos incluídos no estudo. As fontes de financiamento dos estudos individuais não foram reportadas. Não foi investigada a origem da heterogeneidade. O impacto dos vieses não foi levado em consideração nos resultados da metanálise e na síntese das evidências. Os vieses de estudos individuais não foram levados em conta na discussão e interpretação dos resultados, e possíveis vieses de publicação não foram investigados adequadamente. A origem da heterogeneidade não foi discutida. Os trabalhos incluídos apresentavam uma heterogeneidade significativa, avaliada através de análises post hoc dos diferentes subgrupos envolvidos (isto é, quando as análises dos mesmos são feitas após a compilação dos resultados), um método apontado pelo Manual de Revisões Sistemáticas de Intervenções da Cochrane (Higgins \& Green, 2011b) como responsável por frequentes conclusões equivocadas acerca da heterogeneidade dos estudos. Desse modo, a metanálise de Abbass et al. (2014) apresenta conclusões de confiabilidade criticamente baixa. Confira os resultados completos na tabela 3 .

\section{Conclusão}

Após a avaliação da qualidade dos artigos defendidos por Dunker (2021) como sendo a prova cabal da eficácia da psicanálise, obtivemos o resultado de que todos eles ou obtêm a pior classificação possível quando avaliados pelos 
instrumentos de referência, ou não têm um delineamento adequado para responder à questão (como o caso de relatos de experiência e revisões narrativas). $O$ estudo prospectivo/quase-experimento obteve o resultado pelo ROBINS-I de risco de viés crítico. Todos os ensaios clínicos randomizados obtiveram como resultado um alto risco de viés. Todas as revisões sistemáticas e todas as metanálises foram classificadas como fornecendo um nível de confiança criticamente baixo.

Em geral, tais artigos nem mesmo faziam uma avaliação de versões clássicas da psicanálise (freudiana, lacaniana ou kleiniana), mas sim de diferentes tipos de terapias psicodinâmicas, que são um desdobramento da original e estão sob influência de diversos autores (alguns dos quais nem mesmo são reconhecidos como psicanalistas: como Jung). Além disso, entre eles frequentemente se encontravam estudos com terapias manualizadas e com protocolos, o que os enquadra como alvos da crítica que o próprio Dunker (2021) tentou fazer.

Com "prova cabal", pode-se querer dizer muitas coisas diferentes: prova infalível, prova robusta, prova incontestável, e assim por diante. Independente de qual seja o significado, não podemos dizer que tal prova foi encontrada nos artigos referenciados. Nem mesmo podemos dizer que foram encontrados indícios confiáveis a favor da terapia psicanalítica, em uma tentativa mais modesta de expressão. Futuros trabalhos de melhor qualidade são imprescindíveis caso se queira fazer um julgamento sobre a (in)eficácia psicoterápica de terapias psicodinâmicas ou psicanalíticas; mas até lá, não podemos dizer que tais artigos são boas evidências para atestar pura e simplesmente, que dirá "cabalmente", a sua eficácia.

Finalizamos com dois apontamentos mais gerais sobre normas éticas e epistêmicas no que toca à formação de crenças. Primeiramente, para que a psicologia se estabeleça com uma base científica forte, é necessário repensar a pertinência da ideia de que todas as abordagens e psicoterapias devem ser aceitas como equivalentes em nome de uma suposta "tolerância" que ao final acaba por beneficiar apenas aqueles que em cima dela lucram. Ao invés disso, foquemos nas pessoas que buscam o auxílio da Psicologia: o nosso respeito por elas começa com uma busca pelas intervenções que realmente têm maiores chances de serem eficazes para a demanda do contexto, acompanhada do aperfeiçoamento da perícia profissional e da atenção às características particulares daqueles ao nosso cuidado. Isso, por acaso, descreve sucintamente os princípios básicos da Prática Baseada em Evidências.

Segundo, voltemos ao tema dos tratamentos precoces na pandemia, discutido brevemente na seção de Métodos. Alguns dos coautores deste documento fizeram em outro lugar (Andrade \& Ferreira, 2021) uma conexão bem mais estreita entre a conduta de psicanalistas e o fenômeno generalizado atualmente denominado negacionismo. Lembrando, alguns medicamentos (como a Cloroquina e a Ivermectina) foram defendidos como tendo sua eficácia comprovada contra a COVID-19 com base na simples ideia de que há diversos artigos concluindo a sua eficácia; o problema é que eles esmagadoramente são de qualidade deficitária. Muitos psicanalistas (incluindo Dunker (2021)), com toda a razão, criticam e 
combatem essa atitude negacionista extremamente perigosa; no entanto, a atitude muda radicalmente quando o assunto é aplicar o rigor epistêmico ao seu próprio campo de atuação. Vimos neste artigo que os estudos concluindo a eficácia das intervenções psicanalíticas e afins são de qualidade deficitária, de modo que, quando um psicanalista como Dunker os propõe presunçosamente como base sólida na qual apoiar a sua defesa da sua área, não é nada descaridosa a comparação com o negacionismo sobre o tratamento precoce. Não é coerente, para dizer o mínimo, colocar-se contra o negacionismo apenas quando tal postura é mais conveniente. Apenas quando os profissionais da psicologia perceberem isso é que poderemos afirmar que estamos de fato cumprindo nossas demandas éticas e propósitos e demandas como profissão.

\section{Agradecimentos}

Agradecemos especialmente a Willian de Sousa Rodrigues e Luan Rafael Marques de Oliveira, pelo excelente trabalho de revisão e pelas sugestões feitas para o refinamento do trabalho final.

\section{Fontes de Financiamento e Conflito de Interesses}

Não houve fontes de financiamento para o presente trabalho. Clarice, Vitor, Thiago, João, Camila e Gustavo são membros da Associação Brasileira de Psicologia Baseada em Evidências (ABPBE), que representa um movimento que vem realizando críticas a algumas abordagens teóricas e terapêuticas da Psicologia. Observe que esse movimento envolve o ideal da adoção de crenças e atitudes com base nas melhores evidências disponíveis, independente das preferências pessoais do profissional ou pesquisador, e esse mesmo ideal pode ser tratado como uma estratégia para o manejo de possíveis conflitos de interesse não financeiros. Ele também se aplica ao presente estudo: foi acordado com todos os avaliadores a importância da publicação das análises independentemente de seus resultados, além do uso de instrumentos de avaliação bem reconhecidos e a disponibilização pública dos materiais de consenso - uma iniciativa alinhada às práticas de ciência aberta. Desse modo, toda a comunidade disporá de condições para avaliar a pertinência de cada uma das avaliações realizadas.

\section{Contribuições dos Autores}

Clarice de Medeiros Chaves Ferreira: conceituação do trabalho; avaliação das revisões narrativas, sistemáticas e metanálises; redação do manuscrito original; realização de revisão crítica/edição do manuscrito; administração do projeto.

Vitor Douglas de Andrade: conceituação do trabalho; redação do manuscrito original; realização de revisão crítica/edição do manuscrito. 
Thiago Mácimo Pereira: Redação do manuscrito original; avaliação das revisões narrativas, sistemáticas e metanálises.

João Pedro Parreira Rodrigues: Redação do manuscrito original; avaliação dos ensaios clínicos randomizados e do quase-experimento.

Vinícius Figueiredo de Oliveira: avaliação dos ensaios clínicos randomizados.

Camila Batista Peixoto: desenvolvimento da metodologia; organização dos instrumentos; avaliação do quase-experimental.

Gustavo Carvalho Fretta: Redação do manuscrito original; avaliação do relato de experiências e das revisões narrativas.

\section{Referências}

Abbass, A. A., Hancock, J. T., Henderson, J., \& Kisely, S. R. (2006). Short-term psychodynamic psychotherapies for common mental disorders. Cochrane Database of Systematic Reviews, (4). https://doi.org/10.1002/14651858.cd004687.pub3

Abbass, A. A., Kisely, S. R., Town, J. M., Leichsenring, F., Driessen, E., De Maat, S., Gerber, A., Dekker, J., Rabung, S., Rusalovska, S., \& Crowe, E. (2014). Short-term psychodynamic psychotherapies for common mental disorders. Cochrane Database of Systematic Reviews, (7). https://doi.org/10.1002/14651858.cd004687.pub4

Andrade, V. D. \& Ferreira, C. M. C. (2021). Os negacionistas que agora "defendem a ciência". Revista Questão De Ciência.

https://revistaquestaodeciencia.com.br/artigo/2021/06/29/os-negacionistas-que-ag ora-defendem-ciencia

American Psychological Association. (2020). psychodynamic theory. APA Dictionary of Psychology. American Psychological Association.

https://dictionary.apa.org/psychodynamic-theory

Beck, A. T., \& Bhar, S. S. (2009). Analyzing effectiveness of long-term psychodynamic psychotherapy. JAMA, 301(9), 930-930. https://doi.org/10.1001/jama.2009.179

Benedetti, F. (2009). Placebo Effects: understanding the mechanisms in health and disease. Oxford University Press.

Bernardi, R., Fonagy, P., Kächele, H., Leuzinger-Bohleber, M., \& Scarfone, D. (2015). An open door review of outcome and process studies in psychoanalysis (3rd ed., pp. 1-409). International Psychoanalytical Association. Recuperado de https://www.ipa.world/ipa/IPA_Docs/Open\%20Door\%20Review\%20III.pdf

Bhar, S. S., \& Beck, A. T. (2009). Treatment Integrity of Studies That Compare Short-Term Psychodynamic Psychotherapy With Cognitive-Behavior Therapy. Clinical 
Psychology: Science and Practice, 16(3), 370-378.

https://doi.org/10.1111/j.1468-2850.2009.01176.x

Bhar, S. S., Thombs, B. D., Pignotti, M., Bassel, M., Jewett, L., Coyne, J. C., \& Beck, A. T. (2010). Is longer-term psychodynamic psychotherapy more effective than shorter-term therapies? Review and critique of the evidence. Psychotherapy and psychosomatics, 79(4), 208-216. https://doi.org/10.1159/000313689

Boswell, J. F., Sharpless, B. A., Greenberg, L. S., Heatherington, L., Huppert, J. D., Barber, J. P., Goldfried, M. R., \& Castonguay, L. G. (2014). In D. H. Barlow (Ed.), The Oxford Handbook of Clinical Psychology (Updated Edition, pp. 98-127). Oxford University Press, USA.

Cantin, L. (2009) 'An Effective Treatment of Psychosis with Psychoanalysis in Québec City, since 1982', Annual Review of Critical Psychology, 7, pp. 286-319 http://www.discourseunit.com/arcp/7.htm

Chambless, D. L., \& Hollon, S. D. (1998). Defining empirically supported therapies. Journal of consulting and clinical psychology, 66(1), 7-18.

https://doi.org/10.1037//0022-006x.66.1.7

Cioffi, F. (2013). Pseudoscience: The Case of Freud's Sexual Etiology of the Neuroses. In M. Pigliucci \& M. Boudry (Eds.), Philosophy of Pseudoscience: Reconsidering the Demarcation Problem (pp. 321-340). The University of Chicago Press.

Coyne, J. C., Bhar, S. S., Pignotti, M., Tovote, K. A., \& Beck, A. T. (2011). Missed Opportunity to Rectify or Withdraw a Flawed Metaanalysis of Longer-Term Psychodynamic Psychotherapy. Psychotherapy and Psychosomatics, 80(1), 53-54. https://doi.org/10.1159/000317537

Coyne, J. C. (2011). Oops! Another Flawed, Biased Review Article in British Journal of Psychiatry. Psychology Today. Retrieved September 11, 2021, from https://www.psychologytoday.com/intl/blog/the-skeptical-sleuth/201112/oops-anot her-flawed-biased-review-article-in-british-journal

Coyne, J. C. (2014). Bambi meets Godzilla: Independent evaluation of the superiority of long-term psychodynamic therapy. Coyne of the Realm. Retrieved September 11, 2021, from

https://www.coyneoftherealm.com/2014/03/24/bambi-meets-godzilla-independentevaluation-superiority-long-term-psychodynamic-therapy/

Coyne, J. C. (2016). Is psychodynamic therapy an evidence-supported treatment? Critical look at a systematic review raises doubts. Coyne of the Realm. Retrieved 
September 11, 2021, from

https://www.coyneoftherealm.com/2016/01/25/is-psychodynamic-therapy-an-evide nce-supported-treatment-a-look-at-a-systematic-review-raises-doubts/

Driessen, E., Cuijpers, P., de Maat, S. C., Abbass, A. A., de Jonghe, F., \& Dekker, J. J. (2010). The efficacy of short-term psychodynamic psychotherapy for depression: a meta-analysis. Clinical psychology review, 30(1), 25-36.

https://doi.org/10.1016/j.cpr.2009.08.010

Dunker, C. (2021). Psicanálise baseada em evidências | Christian Dunker | Falando nlsso 324. Youtube. https://www.youtube.com/watch?v=CZe1Y-4VunA

Ferreira, C. M. C. (2021). Será a psicanálise uma pseudociência? Reavaliando a doutrina utilizando uma lista de multicritérios. Debates Em Psiquiatria, 11, 1-33. https://doi.org/10.25118/2763-9037.2021.v11.58

Fonagy P. (2015). The effectiveness of psychodynamic psychotherapies: An update. World psychiatry: official journal of the World Psychiatric Association (WPA), 14(2), 137-150. https://doi.org/10.1002/wps.20235

Fonagy, P., Rost, F., Carlyle, J.-anne, McPherson, S., Thomas, R., Pasco Fearon, R. M., Goldberg, D., \& Taylor, D. (2015). Pragmatic randomized controlled trial of long-term psychoanalytic psychotherapy for treatment-resistant depression: The Tavistock Adult Depression Study (TADS). World Psychiatry, 14(3), 312-321. https://doi.org/10.1002/wps.20267

Gladstone, T., Buchholz, K. R., Fitzgibbon, M., Schiffer, L., Lee, M., Voorhees, B. W. V. (2020).Randomized Clinical Trial of an Internet-Based Adolescent Depression Prevention Intervention in Primary Care: Internalizing Symptom Outcomes. International Journal of Environmental Research and Public Health, 17, 1-17. https://doi.org/10.3390/ijerph17217736

Higgins, J. P. T., Savović, J., Page, M. J., \& Sterne, J. A. C. (2019). Revised Cochrane risk-of-bias tool for randomized trials (RoB 2). RoB2 Development Group.

Higgins, J. P. T. \& Green, S. (2011a). Cochrane Handbook for Systematic Reviews of Interventions Version 5.1.0. The Cochrane Collaboration.

https://handbook-5-1.cochrane.org/chapter_10/10_4_4_2_trim and fill.htm

Higgins, J. P. T. \& Green, S. (2011b). Cochrane Handbook for Systematic Reviews of Interventions Version 5.1.0. The Cochrane Collaboration.

https://handbook-5-1.cochrane.org/chapter 9/9 66 interpretation of subgroup an alyses and meta regressions.htm 
Higgins, J. P. T. \& Green, S. (2011c). Cochrane Handbook for Systematic Reviews of Interventions Version 5.1.0. The Cochrane Collaboration. https://handbook-5-1.cochrane.org/chapter 10/10 4443 fail safe n.htm

Hinic, K., Kowalski, M. O., Holtzman, K., \& Mobus, K. (2019). The effect of a pet therapy and comparison intervention on anxiety in hospitalized children. Journal of Pediatric Nursing, 46, 55-61. https://doi.org/10.1016/j.pedn.2019.03.003

Huber, D., Zimmermann, J., Henrich, G., \& Klug, G. (2012). Comparison of cognitive-behaviour therapy with psychoanalytic and psychodynamic therapy for depressed patients - a three-year follow-up study. Zeitschrift fur Psychosomatische Medizin und Psychotherapie, 58(3), 299-316.

https://doi.org/10.13109/zptm.2012.58.3.299

loannidis, J. P. A. (2012). Why Science Is Not Necessarily Self-Correcting.

Perspectives on Psychological Science, 7(6), 645-654.

https://doi.org/10.1177/1745691612464056

Knekt, P., Virtala, E., Härkänen, T., Vaarama, M., Lehtonen, J., \& Lindfors, O. (2016). The outcome of short- and long-term psychotherapy 10 years after start of treatment. Psychological Medicine, 46(6), 1175-1188.

https://doi.org/10.1017/S0033291715002718

Kriston, L., Hölzel, L., \& Härter, M. (2009). Analyzing effectiveness of long-term psychodynamic psychotherapy. JAMA, 301(9), 930-930.

https://doi.org/10.1001/jama.2009.178

Leichsenring, F., Rabung, S., \& Leibing, E. (2004). The efficacy of short-term psychodynamic psychotherapy in Specific psychiatric Disorders. Archives of General Psychiatry, 61(12), 1208-1216. https://doi.org/10.1001/archpsyc.61.12.1208

Leichsenring, F., \& Rabung, S. (2008). Effectiveness of long-term psychodynamic psychotherapy. JAMA, 300(13), 1551-1565.

https://doi.org/10.1001/jama.300.13.1551

Leichsenring, F., \& Rabung, S. (2011a). Double Standards in Psychotherapy Research. Psychotherapy and Psychosomatics, 80(1), 48-51. https://doi.org/10.1159/000315365

Leichsenring, F., \& Rabung, S. (2011b). Long-term psychodynamic psychotherapy in complex mental disorders: Update of a meta-analysis. British Journal of Psychiatry, 199(1), 15-22. https://doi.org/10.1192/bjp.bp.110.082776

Leichsenring, F., Abbass, A., Luyten, P., Hilsenroth, M., \& Rabung, S. (2013). The emerging evidence for long-term psychodynamic therapy. Psychodynamic Psychiatry, 41(3), 361-384. https://doi.org/10.1521/pdps.2013.41.3.361 
Leichsenring, F., \& Klein, S. (2014). Evidence for psychodynamic psychotherapy in specific mental disorders: A systematic review. Psychoanalytic Psychotherapy, 28(1), 4-32. https://doi.org/10.1080/02668734.2013.865428

Leichsenring, F., Leweke, F., Klein, S., \& Steinert, C. (2015). The empirical status of psychodynamic psychotherapy - an update: Bambi's alive and kicking. Psychotherapy and psychosomatics, 84(3), 129-148. https://doi.org/10.1159/000376584

Littell, J. H., \& Shlonsky, A. (2010). Making Sense of Meta-Analysis: A Critique of "Effectiveness of Long-Term Psychodynamic Psychotherapy". Clinical Social Work Journal, 39, 340-346. http://doi.org/cnrh33

National Institute for Health and Clinical Excellence (2009). Depression in adults: the treatment and management of depression in adults. Clinical Guideline 90. London: National Institute for Health and Clinical Excellence.

https://www.nice.org.uk/guidance/cg90

Open Science Collaboration. (2015). Estimating the reproducibility of psychological science. Science, 349(6251), 943-aac4716-8. https://doi.org/10.1126/science.aac4716

Oreskes, N., \& Conway, E. M. (2010). Merchants of doubt: how a handful of scientists obscured the truth on issues from tobacco smoke to global warming (1st ed.). Bloomsbury Press.

Pae C. U. (2015). Why Systematic Review rather than Narrative Review?. Psychiatry investigation, 12(3), 417-419. https://doi.org/10.4306/pi.2015.12.3.417

Pigliucci M. \& Boudry M. (2013). Philosophy of Pseudoscience: Reconsidering the Demarcation Problem. The University of Chicago Press.

Pignotti, M., \& Albright, D. (2010). Mixing apples and oranges and other methodological problems with a meta-analysis of long term psychodynamic psychotherapy. Clinical Social Work Journal, 39(4), 347-354.

https://doi.org/10.1007/s10615-010-0297-y

Pilati, R. (2018). Ciência e pseudociência: por que acreditamos naquilo em que queremos acreditar. Editora Contexto.

Psicolosofia (2021). Psicanálise Baseada em Evidências? Uma Resposta ao Christian Dunker | Psicolosofia \& Implicaç. Filo.. Youtube. https://www.youtube.com/watch?v=wP953VfZGDk 
Roepke, S., \& Renneberg, B. (2009). Analyzing effectiveness of long-term psychodynamic psychotherapy. JAMA, 301(9), 930-930.

https://doi.org/10.1001/jama.2009.180

Serra-Garcia, M., \& Gneezy, U. (2021). Nonreplicable publications are cited more than replicable ones. Science Advances, 7(21), 1-7.

https://doi.org/10.1126/sciadv.abd1705

Shea, B. J., Reeves, B. C., Wells, G., Thuku, M., Hamel, C., Moran, J., Moher, D., Tugwell, P., Welch, V., Kristjansson, E., \&amp; Henry, D. A. (2017). Amstar 2: A critical appraisal tool for systematic reviews that include randomised or non-randomised studies of healthcare interventions, or both. BMJ.

https://doi.org/10.1136/bmj.j4008

Shedler, J. (2010). The efficacy of psychodynamic psychotherapy. American Psychologist, 65(2), 98-109. https://doi.org/10.1037/a0018378

Shevrin, H., Snodgrass, M., Brakel, L. A. W., Kushwaha, R., Kalaida, N. L., \& Bazan, A. (2013). Subliminal unconscious conflict alpha power inhibits supraliminal conscious symptom experience. Frontiers in Human Neuroscience, 7, 1-12. https://doi.org/10.3389/fnhum.2013.00544

Smit, Y., Huibers, M. J. H., loannidis, J. P. A., van Dyck, R., van Tilburg, W., \& Arntz, A. (2012). The effectiveness of long-term psychoanalytic psychotherapy-a meta-analysis of randomized controlled trials. Clinical Psychology Review, 32(2), 81-92. https://doi.org/10.1016/j.cpr.2011.11.003

Sterne J. A. C., Higgins, J. P. T., Elbers R. G., \& Reeves B. C. (2016). Risk Of Bias In Non-randomized Studies of Interventions (ROBINS-I): detailed guidance. development group for ROBINS-I.

Taylor, D. (2018). Psychoanalytic and psychodynamic therapies for depression: The evidence base. Advances in Psychiatric Treatment, 14(6), 401-413. https://doi.org/10.1192/apt.bp.107.004382

Thombs, B. D., Bassel, M., \& Jewett, L. R. (2009). Analyzing effectiveness of long-term psychodynamic psychotherapy. JAMA, 301(9), 930-930.

https://doi.org/10.1001/jama.2009.177

Tolin, D. F., McKay, D., Forman, E. M., Klonsky, E. D., \& Thombs, B. D. (2015). Empirically Supported Treatment: Recommendations for a New Model. Clinical Psychology: Science and Practice, 22(4), 317-338.

https://doi.org/10.1111/cpsp.12122

Town, J. M., Abbass, A., Stride, C. B., \& Bernier, D. (2017). A randomised controlled trial of intensive short-term dynamic psychotherapy for treatment resistant 
depression: The Halifax Depression Study. Journal of Affective Disorders, 214, 15-25. https://doi.org/10.1016/j.jad.2017.02.035

Uol. (2021) Cpi da Covid: Mayra Pinheiro, secretária do Ministério da Saúde. (2021). YouTube. Acessado em 6 de Fevereiro de 2022.

https://www.youtube.com/watch?v=RVZ ZIOd0MI

Vos, J., Craig, M., Cooper, M. (2015). Existential Therapies: A Meta-Analysis of Their Effects on Psychological Outcomes. Journal of Consulting and Clinical Psychology, 83(1), 115-128. http://dx.doi.org/10.1037/a0037167

Yakeley, J. (2018). Psychodynamic psychotherapy: Developing the evidence base.

Advances in Psychiatric Treatment, 20(4), 269-279.

https://doi.org/10.1192/apt.bp.113.012054 


\section{Tabelas}

Tabela 1: Resultados do Consenso com o Robins-I

\begin{tabular}{|l|c|}
\hline \multicolumn{1}{|c|}{ Robins-I - Quase-Experimento } \\
\hline $\begin{array}{l}\text { Domínio } \\
\text { - Viés devido a } \\
\text { confundidores }\end{array}$ & Huber et al., 2012 \\
\hline $\begin{array}{l}\mathbf{2} \text { - Viés na seleção dos } \\
\text { participantes do estudo }\end{array}$ & Sério \\
\hline $\begin{array}{l}\mathbf{3} \text { - Viés na classificação } \\
\text { das intervenções }\end{array}$ & Sério \\
\hline $\begin{array}{l}\mathbf{4} \text { - Viés devido a } \\
\text { desvios das } \\
\text { intervenções propostas }\end{array}$ & Crítico \\
\hline $\begin{array}{l}\mathbf{5} \text { - Viés devido a dados } \\
\text { faltantes }\end{array}$ & Não Informado \\
\hline $\begin{array}{l}\mathbf{6} \text { - Viés na medida dos } \\
\text { resultados }\end{array}$ & \multicolumn{1}{|c|}{ Sério } \\
\hline $\begin{array}{l}\mathbf{7} \text { - Viés na seleção dos } \\
\text { resultados reportados }\end{array}$ & Não Informado \\
\hline \multicolumn{1}{|c|}{ Geral } & Crítico \\
\hline
\end{tabular}

Tabela 2: Resultados do Consenso com o RoB 2

\begin{tabular}{|c|c|c|c|}
\hline \multicolumn{4}{|c|}{ RoB 2 - Ensaios Clínicos Randomizados } \\
\hline Domínio & $\begin{array}{c}\text { Fonagy et al., } \\
2015\end{array}$ & $\begin{array}{l}\text { Knekt et al., } \\
2016\end{array}$ & $\begin{array}{l}\text { Town et al., } \\
2017\end{array}$ \\
\hline $\begin{array}{l}1 \text { - Risco de viés decorrente do } \\
\text { processo de randomização }\end{array}$ & $\begin{array}{c}\text { Certa } \\
\text { Preocupação }\end{array}$ & Baixo & Baixo \\
\hline $\begin{array}{l}\text { 2.1 - Risco de viés devido a desvios } \\
\text { das intervenções pretendidas (efeito } \\
\text { da designação para intervenção) }\end{array}$ & Baixo & Baixo & Baixo \\
\hline $\begin{array}{l}\text { 2.2 - Risco de viés devido a desvios } \\
\text { das intervenções pretendidas (efeito } \\
\text { de aderir à intervenção) }\end{array}$ & $\begin{array}{c}\text { Certa } \\
\text { Preocupação }\end{array}$ & Alto & $\begin{array}{c}\text { Certa } \\
\text { Preocupação }\end{array}$ \\
\hline 3 - Dados dos resultados ausentes & Alto & Alto & Alto \\
\hline $\begin{array}{l}4 \text { - Risco de viés na aferição do } \\
\text { resultado }\end{array}$ & Baixo & Alto & Baixo \\
\hline $\begin{array}{l}5 \text { - Risco de viés na seleção do } \\
\text { resultado relatado }\end{array}$ & Baixo & Alto & $\begin{array}{c}\text { Certa } \\
\text { Preocupação }\end{array}$ \\
\hline Risco de Viés Geral & Alto & Alto & Alto \\
\hline
\end{tabular}


Tabela 3: Resultados do Consenso com o AMSTAR 2

\begin{tabular}{|c|c|c|c|c|c|c|c|c|}
\hline \multicolumn{9}{|c|}{ AMSTAR 2 - Revisões Sistemáticas e Metanálises } \\
\hline Item & $\begin{array}{l}\text { Leichsenring \& } \\
\text { Klein, } 2014\end{array}$ & $\begin{array}{l}\text { Leichsenring et } \\
\text { al., } 2015\end{array}$ & $\begin{array}{l}\text { Leichsenring } \\
\text { et al., } 2004\end{array}$ & $\begin{array}{l}\text { Leichsenring \& } \\
\text { Rabung, } 2008\end{array}$ & $\begin{array}{l}\text { Driessen et } \\
\text { al., } 2010\end{array}$ & $\begin{array}{l}\text { Leichsenring } \\
\text { \& Rabung, } \\
\text { 2011b }\end{array}$ & $\begin{array}{l}\text { Smit et al., } \\
2012\end{array}$ & $\begin{array}{l}\text { Abbass et al., } \\
2014\end{array}$ \\
\hline 1 - Adequação à Estratégia PICO & Não & Não & Sim & Sim & Sim & Não & Sim & Sim \\
\hline 2 - Protocolo registrado antes do início da revisão* & Não & Não & Não & Não & Não & Não & Não & Parcial \\
\hline 3 - Justificativa para Delineamentos Escolhidos & Não & $\operatorname{Sim}$ & Sim & Sim & Não & Não & Sim & Não \\
\hline 4 - Adequação da Pesquisa Bibliográfica* & Não & Não & Não & Não & Não & Não & Sim & Sim \\
\hline 5 - Seleção dos Estudos de Forma Pareada e Independente & Não & Não & Não & Não & Sim & Não & Sim & Sim \\
\hline 6 - Extração dos Dados de Forma Pareada e Independente & Não & Não & Não & Sim & Não & Sim & Não & Sim \\
\hline 7 - Justificativa para Exclusão de Estudos Individuais* & Não & Sim & Não & Não & Não & Não & Não & Sim \\
\hline 8 - Descrição dos Estudos Incluídos & Não & Não & Não & Parcial & Sim & Sim & Parcial & Sim \\
\hline 9 - Risco de Viés dos Estudos Individuais* & Não & Não & Não & Não & Não & Não & Parcial & $\operatorname{Sim}$ \\
\hline 10 - Fontes de Financiamento dos Estudos Individuais & Não & Não & Não & Não & Não & Não & Não & Não \\
\hline 11 - Adequação e Justificação dos Métodos Metanalíticos* & - & - & Não & Não & Não & Não & Não & Não \\
\hline $\begin{array}{l}12 \text { - Avaliação do Impacto do Risco de Viés dos Estudos } \\
\text { Individuais sobre os Resultados da Metanálise }\end{array}$ & - & - & Não & Não & Não & Não & Não & Não \\
\hline $\begin{array}{l}13 \text { - Consideração do risco de viés ao interpretar os resultados da } \\
\text { revisão* }\end{array}$ & Não & Não & Não & Não & Não & Não & $\operatorname{Sim}$ & Não \\
\hline 14 - Discussão e Investigação da Heterogeneidade & Não & Não & Não & Não & Não & Não & Sim & Não \\
\hline $\begin{array}{l}15 \text { - Avaliação da presença e provável impacto do viés de } \\
\text { publicação* }\end{array}$ & - & - & Não & Não & Não & Sim & Não & Não \\
\hline 16 - Declaração e Manejo do Conflito de Interesses dos Autores & Não & Sim & Não & Não & Não & Sim & Não & Sim \\
\hline Classificação Final da Confiança nos Resultados & $\begin{array}{l}\text { Criticamente } \\
\text { Baixa }\end{array}$ & $\begin{array}{l}\text { Criticamente } \\
\text { Baixa }\end{array}$ & $\begin{array}{l}\text { Criticamente } \\
\text { Baixa }\end{array}$ & $\begin{array}{l}\text { Criticamente } \\
\text { Baixa }\end{array}$ & $\begin{array}{c}\text { Criticamente } \\
\text { Baixa }\end{array}$ & $\begin{array}{c}\text { Criticamente } \\
\text { Baixa }\end{array}$ & $\begin{array}{l}\text { Criticamente } \\
\text { Baixa }\end{array}$ & $\begin{array}{l}\text { Criticamente } \\
\text { Baixa }\end{array}$ \\
\hline
\end{tabular}

*Item crítico. 